E. de Lucas-Gil, P. Leret, M. Monte-Serrano, J.J. Reinosa, E. Enríquez, A. Del Campo, M. Cañete, J. Menéndez, J.F. Fernández, F. Rubio-Marcos, ZnO Nanoporous Spheres with Broad-Spectrum Antimicrobial Activity by Physicochemical Interactions, ACS Appl. Nano Mater. 1 (2018) 3214-3225. doi:10.1021/acsanm.8b00402

\title{
ZnO Nanoporous Spheres with Broad-Spectrum Antimicrobial Activity by Physicochemical Interactions
}

\author{
Eva de Lucas-Gil ${ }^{1,2, *}$, Pilar Leret ${ }^{1}$, Mercedes Monte-Serrano², Julián J. Reinosa ${ }^{1}$, Esther \\ Enríquez ${ }^{1}$, Adolfo Del Campo ${ }^{1}$, Magdalena Cañete ${ }^{3}$, Javier Menéndez ${ }^{2}$, José F. Fernández ${ }^{1}$ \\ and Fernando Rubio-Marcos ${ }^{1}$
}

${ }^{1}$ Electroceramic Department, Instituto de Cerámica y Vidrio, CSIC, Kelsen 5, 28049 Madrid, Spain

${ }^{2}$ NanoBioMatters Bactiblock, NanoBioMatters Industries S.L., Louis Pasteur 11, 46980 Paterna, Valencia, Spain

${ }^{3}$ Biology Department, Faculty of Sciences. Universidad Autónoma de Madrid, Darwin 2, 28049 Madrid Spain

*Correspondence and requests for materials should be addressed to E. L-G. (email: elucas@icv.csic.es)

\begin{abstract}
The extensive range of applications where synthetic nanomaterials are nowadays used is causing a huge commercial market. An incipient use of these nanomaterials arises from the need to generate alternative antimicrobial agents, anticipating the development of resistant microorganisms. Here, we show a nanostructured $\mathrm{ZnO}$ with antimicrobial properties and low-cytotoxicity based on a nanoparticles arrangement by controlling the formation of sintering-neck into nanoporous spheres. The antimicrobial effectiveness of $\mathrm{ZnO}$ spheres is tested in a broad-spectrum of microorganisms such as fungi, Gram-negative and Gram-positive bacteria. The hierarchical structures show highly effective antimicrobial activity at low concentrations and in relatively short action times (24-72h). We demonstrate that the enhanced antimicrobial properties against microorganisms are ascribed to a combining of both physical and chemical interactions between microorganism and $\mathrm{ZnO}$. The approximation mechanism between microorganism and $\mathrm{ZnO}$ is provided through electrostatic forces (physical interaction) which, thanks to the ZnO-microorganism proximity, promote a rapid release of zinc cations and the reactive oxygen species penetration into microorganisms (chemical interaction). We believe that this work provides insights on the mechanisms underlying the interactions $\mathrm{ZnO}$ microorganism and possess a combined action mechanism for which nanostructured $\mathrm{ZnO}$ is so effective to combat microorganisms.
\end{abstract}

KEYWORDS: $\mathrm{ZnO}$, cluster, nanoporous spheres, antimicrobial properties, physicochemical action 
E. de Lucas-Gil, P. Leret, M. Monte-Serrano, J.J. Reinosa, E. Enríquez, A. Del Campo, M. Cañete, J. Menéndez, J.F. Fernández, F. Rubio-Marcos, ZnO Nanoporous Spheres with Broad-Spectrum Antimicrobial Activity by Physicochemical Interactions, ACS Appl. Nano Mater. 1 (2018) $3214-3225$. doi:10.1021/acsanm.8b00402.

\section{Introduction}

Nanoscience has experienced a rapidly developing worldwide in the $21^{\text {st }}$ century from basic science to industry. The main characteristics of nanomaterials are its extremely small size (at least one dimension smaller than 100 $\mathrm{nm})$, large surface area and high reactivity. All these characteristics are far from the physicochemical properties of the same material in bulk form. For this reason, nanomaterials are used in a wide variety of commercial products such as electronic components, gas sensing, solar cells, catalysis, clothing, cosmetics and food. ${ }^{1-6}$ One of the many applications where nanoscale materials have emerged stronger is as novel antimicrobial agents. The need for these nanomaterials resides in the emergence of bacterial resistance to classical antibiotics. ${ }^{7}$ Searching and developing new antibiotics, it is a costly process and its effectiveness will only be temporary before resistance reappears again. ${ }^{8}$ Therefore, alternatives antibiotics with different properties from those known and used will make a difference in this constant struggle against the resistance of microorganisms.

Some metals like silver $(\mathrm{Ag})$, copper $(\mathrm{Cu})$, zinc $(\mathrm{Zn})$, and magnesium $(\mathrm{Mg})$ have been used to treat diseases, since ancient times. ${ }^{9}$ Taking into consideration the physicochemical properties modulation of nanomaterials, generating new antimicrobial agents based on inorganic nanoparticles could be the solution to the emergent antimicrobial resistance that we are now facing. To date, one of the most investigated and used nanomaterial in health care with antimicrobial properties is Ag nanoparticles (NPs). ${ }^{10,11}$ The literature reports the release of $\mathrm{Ag}^{+}$ions and the generation of reactive oxygen species (ROS) as the main factors of Ag NPs antimicrobial action. ${ }^{9,11,12}$ These factors are closely related to the oxidation process of $\mathrm{Ag}(0)$ to $\mathrm{Ag}^{+}$, which could in turn produce ROS. ${ }^{12,13} \mathrm{Ag}$ NPs attack directly to bacterial membrane, altering its properties and ultimately causing the cell death. ${ }^{14}$ Therefore, Ag NPs main antibacterial mechanism is based on the release of toxic metal ions (that is, chemical interactions). To increase the antimicrobial ability, Ag NPs are typically designed to possess small size and high oxidation state. ${ }^{9}$ However, despite being an extended antimicrobial material, Ag NPs have potential drawbacks such as their cost, durability and the environmental impact caused by both the cation and the ROS release. In addition, recently, it has also been evidenced bacterial resistance to Ag NPs. ${ }^{15}$ Coupled with this, the high efficiency of Ag NPs is mostly tested for bacteria, without taking into account another important group within the microorganisms such as fungi. 
E. de Lucas-Gil, P. Leret, M. Monte-Serrano, J.J. Reinosa, E. Enríquez, A. Del Campo, M. Cañete, J. Menéndez, J.F. Fernández, F. Rubio-Marcos, ZnO Nanoporous Spheres with Broad-Spectrum Antimicrobial Activity by Physicochemical Interactions, ACS Appl. Nano Mater. 1 (2018) $3214-3225$. doi:10.1021/acsanm.8b00402.

In line with the above, it is necessary to develop more sustainable antimicrobial agent whit broad-spectrum effectiveness (including bacteria and fungi). In recent years, the use of inorganic oxides like antimicrobial agents has attracted interest due to their durability, stability and less toxicity than organic compounds. Among the wide variety of metal oxides, one of the most effective is $\mathrm{ZnO} \cdot{ }^{16-18}$ The literature reports widely the $\mathrm{ZnO}$ effectiveness against different microorganism such as bacteria ${ }^{19-21}$ or fungi. ${ }^{22,23}$ Many researchers correlated the greater antimicrobial activity of $\mathrm{ZnO}$ NPs with the size of the constituent particles, being more effective the smaller size. ${ }^{24-26}$ However, a hierarchical organization of nanoparticles shows a series of advantages with respect to free nanostructures. The main benefit of hierarchical structures is to combine the features of nanoscale building blocks with the micrometric organization, showing unique properties different from those of the mono-morphological structures. ${ }^{27}$ In addition, another advantage of hierarchical structures is related to the possibility of controlling their morphology, orientation, porosity and surface because these parameters determine the optical, electronic, and catalytic responses of the materials. ${ }^{28}$ Moreover, the hierarchical organization should be interpreted as an improvement from the point of view of materials safety. Keeping the properties of nanometric materials, but structured in micrometric size facilitates the safety in handling and manufacturing processes.

Although the study of the antimicrobial activity of $\mathrm{ZnO}$ is reported, little is known about its action mechanism against microorganisms. Two main streams of actions related to the antimicrobial mechanism are reported: physical and chemical interactions. ${ }^{5,29,30}$ Respect to physical actions, authors suggest various interactions with microorganisms such as electrostatic effect, abrasion of membrane envelope and penetration of particles. ${ }^{31}$ According to chemical actions, there are two possibilities: reactive oxygen species (ROS) production ${ }^{32,33}$ and $\mathrm{Zn}^{2+}$ release. ${ }^{34}$ However, despite this wide range of interactions, it is difficult to discern which is the exact action mechanism of ZnO NPs. ${ }^{35,36}$

In this work, we aim to synthesize $\mathrm{ZnO}$ nanoparticles with hierarchical structure for antimicrobial applications. To anticipate the possible problems that nanoparticles can cause, ${ }^{37,38}$ we have organized hierarchically nanoparticles in nanoporous spheres. Nanoporous spheres have shown advantages in durability as catalyst supports and thereafter in sensing, biomedical, environmental and energy-related applications. ${ }^{39}$ In order to obtain the antimicrobial potential of nanostructured $\mathrm{ZnO}$, different tests have been carried out using bacteria 
E. de Lucas-Gil, P. Leret, M. Monte-Serrano, J.J. Reinosa, E. Enríquez, A. Del Campo, M. Cañete, J. Menéndez, J.F. Fernández, F. Rubio-Marcos, ZnO Nanoporous Spheres with Broad-Spectrum Antimicrobial Activity by Physicochemical Interactions, ACS Appl. Nano Mater. 1 (2018) $3214-3225$. doi:10.1021/acsanm.8b00402.

and fungi. We demonstrate that our $\mathrm{ZnO}$ nanoporous spheres are able to maintain antimicrobial activity despite its submicronic size. Hence, we discuss the main antimicrobial interactions of nanostructured $\mathrm{ZnO}$ against microorganisms. Finally, our study provides a great basis to get knowledge about the chemical and physical synergistic action mechanism by which this new hierarchical structure is more effective and less cytotoxic than ZnO NPs.

\section{Results and Discussion}

Soft chemical synthesis to obtain nanostructured $\mathrm{ZnO}$. New $\mathrm{ZnO}$ (thereafter NS-ZnO, NanoStructured $\mathrm{ZnO}$ ) is prepared by a soft chemistry method starting from a micrometric $\mathrm{ZnO}$. The experimental details are schematically shown in Fig. 1. After reaction, the product is thermally treated at $500^{\circ} \mathrm{C}$ under air atmosphere for a short time of $5 \mathrm{~min}$. A structural characterization of the obtained product is performed by X-ray diffraction (XRD) and Fourier Transform Infrared (FTIR). XRD pattern (Fig. S1a) displays that only a crystalline structure is identified after thermal treatment of the sample. The position and intensity of diffraction peaks match to hexagonal wurtzite structure ZnO (JCPDS Card No. 36-1451). The full width at half maximum (FWHM) of peaks reveals a reduction in crystallite size according to the Scherrer formula for nanostructured $\mathrm{ZnO}$ in comparison with the starting ZnO. FTIR spectrum (Fig. S1b) shows four groups of absorption IR bands. The most strong absorption IR band appears around $495 \mathrm{~cm}^{-1}$ where three peaks are deconvoluted at 437, 494 and $534 \mathrm{~cm}^{-1}$ ascribed to different $\mathrm{Zn}-\mathrm{O}$ morphologies such as mainly sphere, plate or rod. ${ }^{40}$ Other IR bands are identified and are assigned to some impurities. A broad IR band at $3458 \mathrm{~cm}^{-1}$ is assigned to the $\mathrm{O}-\mathrm{H}$ stretching mode $(\mathrm{v}(\mathrm{OH}))$ of the hydroxyl group. The IR bands observed at 1632, 1520 and $1387 \mathrm{~cm}^{-1}$ are typical of $\mathrm{v}_{3}$ of $\mathrm{C}-\mathrm{O}$ and $\mathrm{C}=\mathrm{O}$, carbonate groups. Also, IR bands around 1000 to $700 \mathrm{~cm}^{-1}$ correspond to carbonate groups $\left(\mathrm{v}_{1}, \mathrm{v}_{2} \mathrm{y} \mathrm{v}_{4}\right){ }^{41}$ The structural characterization indicates a predominant phase of $\mathrm{ZnO}$ and rest of synthesis reaction impurities. As demonstrated by FTIR, these impurities are categorized as hydroxyl and carbonate groups. Possibly, impurities come from residues of reaction intermediates after annealing, being kidnapped into the $\mathrm{ZnO}$ structure. In addition, X-ray absorption near edge structure (XANES) experiment in transmission mode was performed to determine the oxidation state of $\mathrm{Zn}$ in samples. As shown in Fig. S1c, the difference between $\mathrm{Zn}$ foil $(9659 \mathrm{eV})$ and NS-ZnO spectra indicates a change in oxidation state from $\mathrm{Zn}(0)$ to $\mathrm{Zn}(\mathrm{II})$. The comparative spectra with two $\mathrm{ZnO}$ commercial references confirm the oxidation state of $\mathrm{Zn}^{2+}$. 
E. de Lucas-Gil, P. Leret, M. Monte-Serrano, J.J. Reinosa, E. Enríquez, A. Del Campo, M. Cañete, J. Menéndez, J.F. Fernández, F. Rubio-Marcos, ZnO Nanoporous Spheres with Broad-Spectrum Antimicrobial Activity by Physicochemical Interactions, ACS Appl. Nano Mater. 1 (2018) 3214-3225. doi:10.1021/acsanm.8b00402.

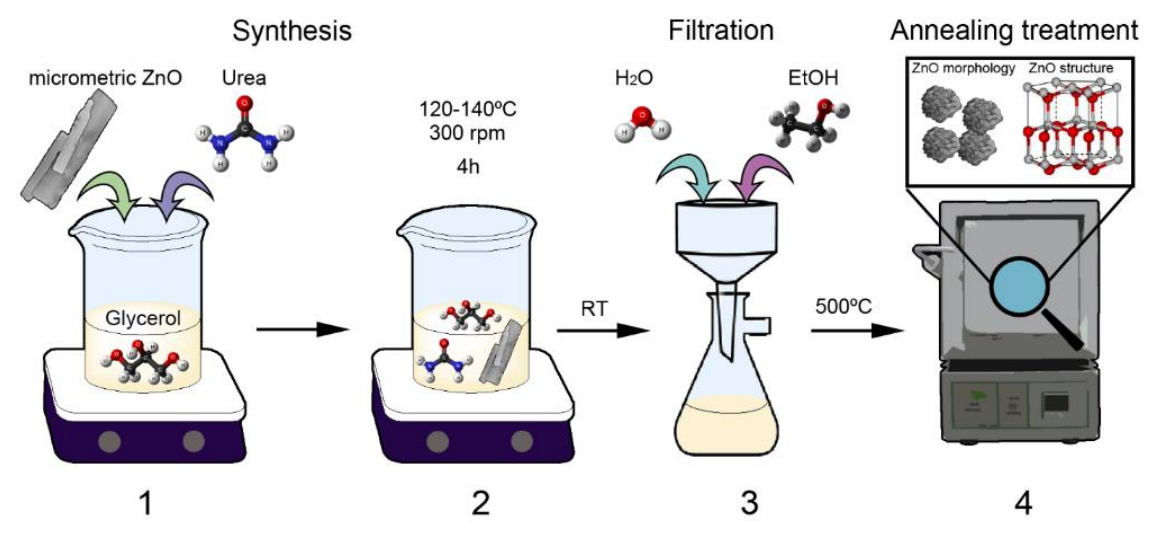

Figure 1 | Scheme of the synthesis process of the nanostructured ZnO. (1) Addition of micrometric zinc oxide (6 wt.\%) and urea (3.6 $\mathrm{mol}$ ) to glycerol $(3.6 \mathrm{~mol})$, under stirring at room temperature. (2) The resulting solution was heated in an oil bath at $120-140^{\circ} \mathrm{C}$ and stirred at $300 \mathrm{rpm}$ for $4 \mathrm{~h}$ at atmospheric pressure. (3) Cooling to room temperature the solution, filtration and washed with water and ethanol several times to remove impurities. (4) The product was thermally treated at $500^{\circ} \mathrm{C}$ for a short time, $5 \mathrm{~min}$, in the air.

The union confers stable morphologies: nanoparticles hierarchically organized. The morphology of synthesized NS-ZnO is studied by field emission scanning electron microscopy (FE-SEM) and transmission electron microscope (TEM), Fig. 2. The Fig. 2a shows an organized structure of synthesized NS-ZnO in clusters or agglomerates. These clusters have a homogeneously pseudo-spherical morphology throughout the sample. From Fig. $\mathbf{2 b}$ it is possible to closely observe the nanoparticles' clusters that show incipient sintering necks between particles. These nanoparticles are hierarchically organized giving the characteristic pseudo-spherical form of the clusters. Therefore, the cluster's morphology gets the most stable shape achieved in nature, the sphere. In addition, spherical morphology offers some advantages such as stabilization of electrostatic charges or high surface area, among others. ${ }^{39}$ Fig. $\mathbf{2 b}$ also shows an incipient sintering necks formation between nanoparticles. The extent of the sintering necks is controlled by the short duration of the thermal treatment. In this case, the sintering process is not completed, leaving the sinterization in the first stages. The initial stage of sintering would begin as soon as some degree of atomic mobility is achieved. During this stage, sharply concave necks begin to form between the particles and the amount of densification is small, so there is a high porosity. ${ }^{42}$ Besides, in the intermediate stage, the microstructure consists of a three-dimensional interpenetrating network of solid particles and continuous, channel-like pores. ${ }^{43}$ If sintering was completed, the channel-like pores break down into isolated closed voids reducing the porosity. Therefore, the incipient sintering necks cohere the hierarchical structure of these agglomerates and provide some porosity to the structure. To check the porosity of NS-ZnO, a study of the $\mathrm{N}_{2}$ adsorption-desorption isotherm is performed (see Fig. S2a). The NS-ZnO textural features (Fig. S2b) show a BET surface area, a pore volume and a pore average size of $20.72 \mathrm{~m}^{2} \mathrm{~g}^{-1}, 0.18 \mathrm{~cm}^{3} \mathrm{~g}^{-1}$ 
E. de Lucas-Gil, P. Leret, M. Monte-Serrano, J.J. Reinosa, E. Enríquez, A. Del Campo, M. Cañete, J. Menéndez, J.F. Fernández, F. Rubio-Marcos, ZnO Nanoporous Spheres with Broad-Spectrum Antimicrobial Activity by Physicochemical Interactions, ACS Appl. Nano Mater. 1 (2018) $3214-3225$. doi:10.1021/acsanm.8b00402.

and $34 \mathrm{~nm}$, respectively. Therefore, according to Jaroniec et al. the morphology obtained of NS-ZnO is defined as nanoporous solid spheres. ${ }^{39}$ Moreover, new porosity parameters have been numerically defined for the $\mathrm{ZnO}$, such as pore volume. The Fig. $2 \mathrm{c}$ displays the cluster size distribution. As shown, the distribution varies between 300 and $900 \mathrm{~nm}$, with an average of $590 \mathrm{~nm}$. The $\mathrm{ZnO}$ cluster structure stability of NS-ZnO was checked by an ultrasonication study. It is verified that after $10 \mathrm{~min}$ of ultrasound the structure keeps the hierarchical form (Fig S3) due to nanoparticle unions by sintering necks. The main difference between hierarchical structure and aggregates of $\mathrm{ZnO}$ nanoparticles is the stability of the structure, i.e. the ability to disperse nanoparticles in suspension. In NS-ZnO the nanoparticles are linked by sintering necks, preventing the dispersion of nanoparticles, so this is a hierarchical structure. The strength of sintering necks makes the sphere structures stable in solution. The primary particle size distribution has an average value of ca. $63 \mathrm{~nm}$ and always lower than $100 \mathrm{~nm}$, which is shown in Fig. 2d. The Fig. 2e allows observing clearly and unequivocally the hierarchical organization of $\mathrm{ZnO}$ nanoparticles. Besides, a detailed inspection of Fig. 2e confirms the cluster structures about 500-600 nm in diameter. A close study of a particle is shown in Fig. 2f. The determination of particle lattice spacing of $\sim 1.628 \AA$ is indexed as the ZnO (110) plane according to JCPDS Card No. 79-0206. This result supports the phase assignment of the ZnO phase by XRD in Fig.S1a. This fact allows us to confirm the nanometric character of the hierarchized particles. A morphological study of former $\mathrm{ZnO}$ (Fig. S4) is performed to compare its typical morphology of micrometric $\mathrm{ZnO}$ with the NS-ZnO. The main structure observed is hexagonal prisms with lengths of 1-2 $\mu$ m. Additionally, other smaller nearly hexagonal particles compose the starting $\mathrm{ZnO}$ morphology. For all that, the morphological study proves that the so obtained NS-ZnO is free of unreacted hexagonal $\mathrm{ZnO}$ microparticles. Furthermore, the obtained $\mathrm{ZnO}$ is contrasted with a typical morphology of nanometric ZnO (Fig. S5). The Fig. S5 shows desegregated primary particles with sizes of 15$30 \mathrm{~nm}$ for the nanometric $\mathrm{ZnO}$. Conversely, the new morphology of synthesized NS-ZnO is composed of hierarchically organized nanoparticles in pseudo-spherical clusters as nanoporous spheres. As a result, the so obtained $\mathrm{ZnO}$ spheres reduce drastically the presence of isolated nanoparticles (NPs). 
E. de Lucas-Gil, P. Leret, M. Monte-Serrano, J.J. Reinosa, E. Enríquez, A. Del Campo, M. Cañete, J. Menéndez, J.F. Fernández, F. Rubio-Marcos, ZnO Nanoporous Spheres with Broad-Spectrum Antimicrobial Activity by Physicochemical Interactions, ACS Appl. Nano Mater. 1 (2018) $3214-3225$. doi:10.1021/acsanm.8b00402.
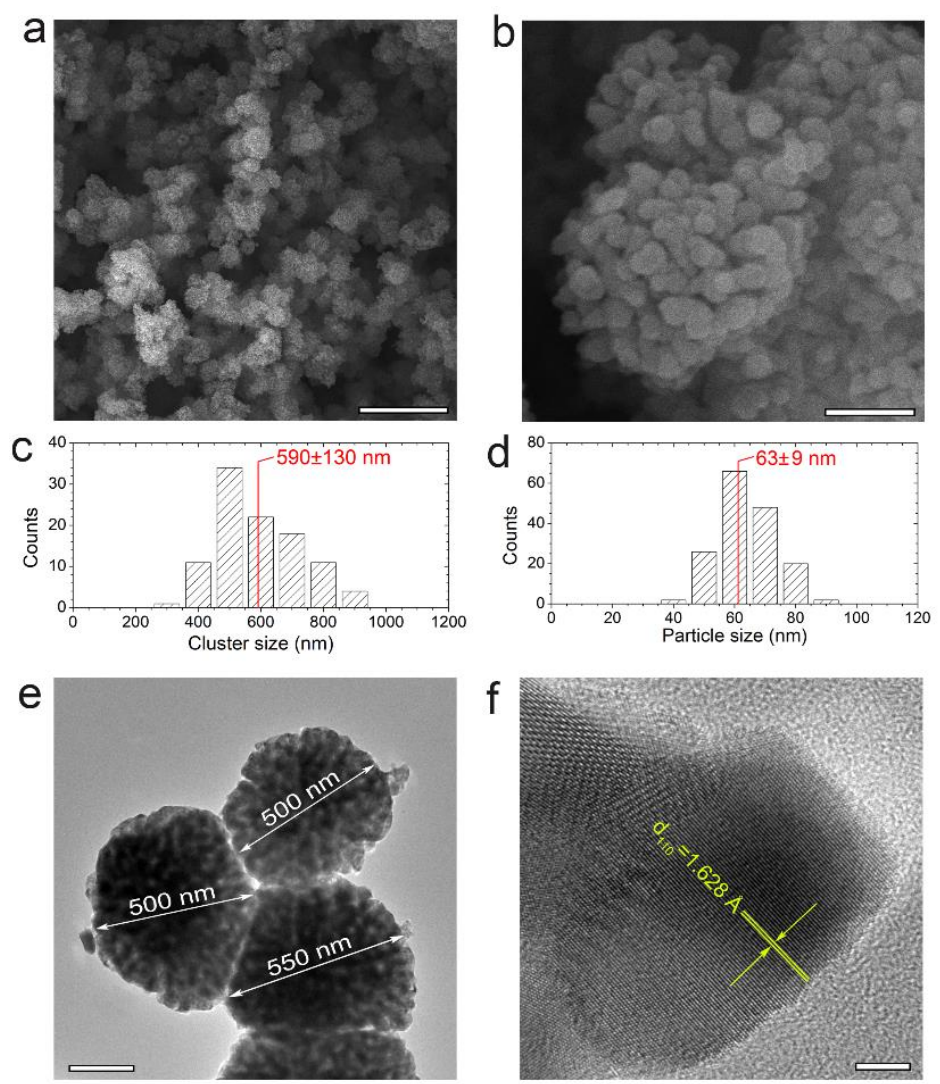

Figure 2 | Morphological characterization of synthesized NS-ZnO. A generic study by FE-SEM $(\mathbf{a}, \mathbf{b})$ show the preferential spherical cluster morphology of the sample. Scale bar of the panel $\mathbf{a}$ is $2 \mu \mathrm{m}$ and panel c is $200 \mathrm{~nm}$. Additionally, below each panel $(\mathbf{a}, \mathbf{b})$ is indicated the population distribution of clusters (c) and particles (d), having $590 \mathrm{~nm}$ and $63 \mathrm{~nm}$ in mean size, respectively. In TEM micrographs, it can be observed the hierarchical organization of nanoparticles forming pseudo-spherical agglomerates (e) and the lattice spacing of the $\mathrm{ZnO}$ nanoparticles (f). Scale bars of panels $\mathbf{e}$ and $\mathbf{f}$ are $200 \mathrm{~nm}$ and $5 \mathrm{~nm}$, respectively.

Finding a potential technological application of the $\mathrm{ZnO}$ nanoporous spheres: antimicrobial capabilities.

The broad antimicrobial activity of NS-ZnO is studied by two tests: fungicidal and bactericidal. For antifungal activity, the NS-ZnO confronts a colony of Aspergillus niger (CECT 2807), see Fig. S6. To establish the fungicidal potential, a Kirby-Bauer method is performed. In this method, the sporulation inhibition diameter (SID) of the fungus is measured. To have a clear idea of the NS-ZnO benefits, results are compared with two different size reference materials, micro and nanometric ZnO. Fig. S6a-c show the SID photographs of micro-, nano- and NS$\mathrm{ZnO}$, respectively. These results collected in Fig. S6d, display the antifungal efficacy of each $\mathrm{ZnO}$ compound. Remarkably, the $\mathrm{ZnO}$ nanoporous spheres improve the antifungal properties of microZnO used as starting material. Besides, the NS-ZnO keeps practically same activity values than nanoZnO. Respect to antibacterial activity (Fig. 3), the $\mathrm{ZnO}$ nanoporous spheres effectiveness is tested against two bacteria: Escherichia coli (CECT 516) and Staphylococcus aureus (CECT 240). E. coli is a rod-shaped Gram-negative bacterium of about $1 \mu \mathrm{m}$ width 
E. de Lucas-Gil, P. Leret, M. Monte-Serrano, J.J. Reinosa, E. Enríquez, A. Del Campo, M. Cañete, J. Menéndez, J.F. Fernández, F. Rubio-Marcos, ZnO Nanoporous Spheres with Broad-Spectrum Antimicrobial Activity by Physicochemical Interactions, ACS Appl. Nano Mater. 1 (2018) $3214-3225$. doi:10.1021/acsanm.8b00402.

and $3 \mu \mathrm{m}$ long and generally, they are part of groups or colonies (Fig. 3a). The $\mathrm{ZnO}$ antibacterial activity against E. coli is performed by the Macrodilution method from the National Committee of Clinical Laboratory Standards (NCCLS) with some modifications. All tests are realized with three different $\mathrm{ZnO}$ materials: micrometric, nanometric and nanostructured. Fig. $\mathbf{3 b}$ shows the colony forming units (CFU) of bacteria after adding only 3 ppm of $\mathrm{ZnO}$ and subsequent incubation for $24 \mathrm{~h}$ at $37^{\circ} \mathrm{C}$. In addition, decreasing $\mathrm{CFU}$ of initial bacteria count (referred to as control) is calculated as the antimicrobial activity value (denoted as R). As shown, the behavior of micro and nanoZnO decreases the bacterial population, reaching acceptable R values about 2 . However, the action of NS-ZnO inhibits bacterial growth to excellent $\mathrm{R}$ values greater than 3.5. To understand how the presence of synthesized NS-ZnO affects to bacteria structure, FE-SEM is performed. Micrographs of $E$. coli after treating by $\mathrm{ZnO}$ nanoporous spheres (Fig. 3c) shows structural damage, pointed with arrows. The bacterium walls are wrinkled and flattened thanks to the direct contact with the $\mathrm{ZnO}$ hierarchical structures. As a possible result, these abnormal textures lead to membrane rupture and finally to cell death.

The other microorganism employed in this test is S. aureus. It is a round-shaped Gram-positive bacterium of about $0.5 \mu \mathrm{m}$ in diameter (Fig. $\mathbf{3 d}$ ). S. aureus is predominantly organized in groups or colonies. The S. aureus antibacterial study reveals a similar behavior than Gram-negative E. coli (Fig. 3e). Newly, R values of references micro and nanometric are around 2. The extraordinary $\mathrm{R}$ value near to 3.5 of NS-ZnO shows a robust antibacterial activity against $S$. aureus. This amazing synthesized NS-ZnO behavior can be observed by FE-SEM images in Fig. 3f. These micrographs display how NS-ZnO clusters surround and adhere to the bacterial wall. This action probably causes disturbances in the cell envelope, the collapse of the bacteria and eventually the death. As shown in Fig. 3c and f, the $\mathrm{ZnO}$ clusters keep the hierarchical structure, although the ZnO clusters are in contact with microorganisms. 
E. de Lucas-Gil, P. Leret, M. Monte-Serrano, J.J. Reinosa, E. Enríquez, A. Del Campo, M. Cañete, J. Menéndez, J.F. Fernández, F. Rubio-Marcos, ZnO Nanoporous Spheres with Broad-Spectrum Antimicrobial Activity by Physicochemical Interactions, ACS Appl. Nano Mater. 1 (2018) 3214-3225. doi:10.1021/acsanm.8b00402.
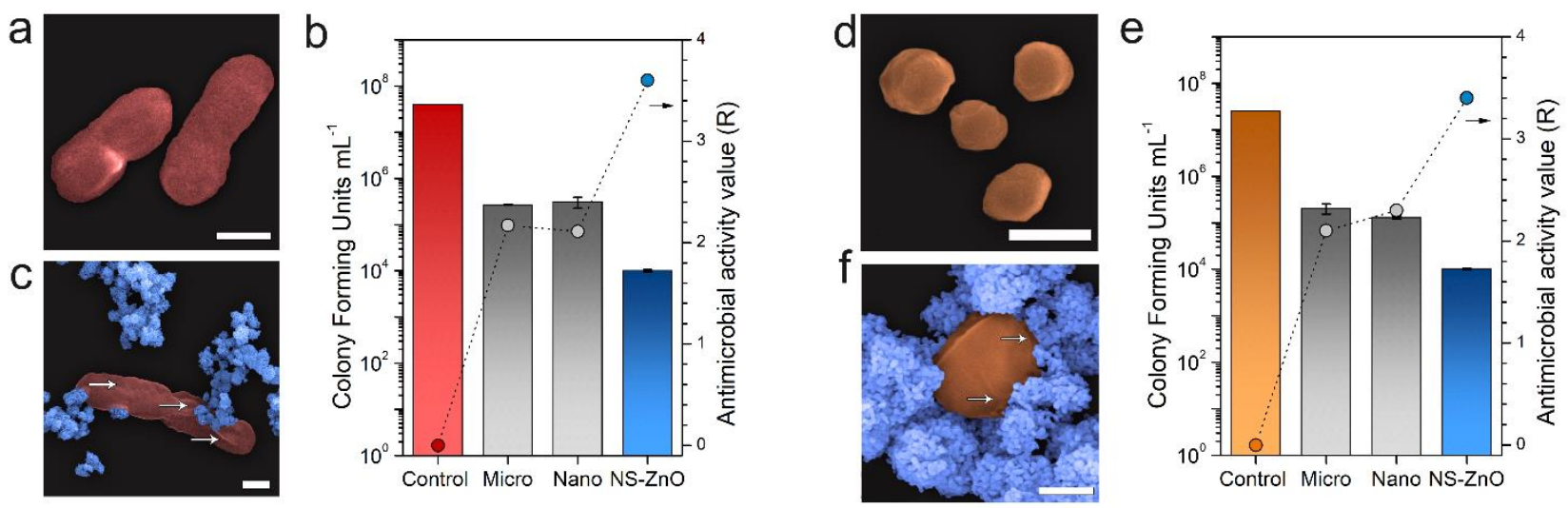

Figure 3 | Antibacterial study of synthesized NS-ZnO against E. coli and S. aureus. The damage for the action of NS-ZnO are displayed in FE-SEM micrographs of E. coli before (a) and after (c) incorporation of ZnO. Colored micrographs have been selected to facilitate the identification of microorganisms and particles. Scale bar of the panels a and $\mathbf{c}$ is $1 \mu \mathrm{m}$. The graph $\mathbf{b}$ shows the antibacterial activity expressed as colony forming units per $\mathrm{mL}\left(\mathrm{CFU} \mathrm{mL} \mathrm{mL}^{-1}\right)$ and the value of antimicrobial activity $(\mathrm{R})$ against E. coli. The initial bacteria count (control) is represented by red, NS-ZnO is symbolized by blue and two reference sizes (micro and nanoZnO) are denoted by gray. FE-SEM micrographs represent $S$. aureus (d) and damage by NS-ZnO (f). The structural damage of bacteria, both E. coli and S. aureus are pointed by white arrows. Scale bar of the panels $\mathbf{d}$ and $\mathbf{f}$ is $500 \mathrm{~nm}$. The graph e represents the antibacterial activity and the value of antimicrobial activity (R) against S. aureus without $\mathrm{ZnO}$ (control, orange) or with references (micro and nanoZnO, gray) and NS-ZnO (blue). Each column represents an average of duplicate measurements for 3 ppm concentration of $\mathrm{ZnO}$. CFU data are shown with mean values and standard error bars.

A breakdown of known antimicrobial mechanisms. The next challenge is to understand the action mechanisms of NS-ZnO against bacteria and fungi that give an exceptional antimicrobial activity. As reflected in the literature, different mechanisms could contribute to the antimicrobial ZnO behavior. ${ }^{5,29,30}$ The most important mechanisms correspond to physical and chemical interactions. ${ }^{31}$ Within physical interactions are electrostatic effect, abrasion of membrane envelope and penetration of particles through the cell. Moreover, a recent study shows electric effect produced by $\mathrm{ZnO}$ microparticles against microorganisms. ${ }^{44}$ The principal chemical interactions are reactive oxygen species (ROS) production and $\mathrm{Zn}^{2+}$ release. Regarding physical way, NS-ZnO manifests a clear cell wall attraction for Gram-negative (Fig. 3c) and Gram-positive bacteria (Fig. 3f). Also Fig. 3 displays that bacteria suffer abrasion of the membrane envelope as wrinkles or blebs. To determine the role of chemical interactions, two studies are realized: a) ROS appearance by photocatalysis and b) the effect of the $\mathrm{Zn}^{2+}$ release. During a photocatalysis process, the hydroxyl radicals $\left(\mathrm{OH}^{*}\right)$ and superoxide anion radicals $\left(\mathrm{O}_{2}^{-\bullet}\right)$ play the main role as active species in the oxidation of dyes. ${ }^{45}$ To achieve the ROS generation is necessary to irradiated $\mathrm{ZnO}$ by light with energy greater than or equal to its band gap (3.37 eV). This energy allows the excitation of an electron in the valence band to the conduction band which generates a hole in the valence band ${ }^{46}$ Finally, holes can react with water adhering to the surfaces of ZnO nanostructures forming ROS, such 
E. de Lucas-Gil, P. Leret, M. Monte-Serrano, J.J. Reinosa, E. Enríquez, A. Del Campo, M. Cañete, J. Menéndez, J.F. Fernández, F. Rubio-Marcos, ZnO Nanoporous Spheres with Broad-Spectrum Antimicrobial Activity by Physicochemical Interactions, ACS Appl. Nano Mater. 1 (2018) $3214-3225$. doi:10.1021/acsanm.8b00402

as hydroxyl and superoxide anion radicals, which degrade organic dye. ${ }^{27,46-48}$ The reaction mechanism is more detailed in Supporting Information. For these reasons, we study the ROS generation power of nanostructured $\mathrm{ZnO}$ by a photocatalytic test. In our case, the photocatalytic performance was evaluated by photodegradation of a standard organic dye, methyl orange (MO), under UV light irradiation. Fig. 4 displays the degradation evolution of MO over time after addition of NS-ZnO. The ultraviolet-visible (UV-vis) spectrum, Fig. 4a, shows the variation of maximum absorption band at $463 \mathrm{~nm}$, methyl orange typical wavelength. With these data, the degradation percentage is calculated according to Beer-Lambert law (Fig. 4b). As shown in Fig. $\mathbf{4 b}$, at short times (10-30 $\mathrm{min})$ no degradation signatures are observed. From 60 minutes, the maximum absorbance at 463 nm decreases gradually achieving $90 \%$ degradation of the dye after irradiation for $5 \mathrm{~h}$. The photodegradation NS-ZnO behavior is compared with the obtained for microZnO and nanoZnO (Fig. S7). As shown, microZnO degrades completely $\mathrm{MO}$ dye and nanoZnO displays $90 \%$ degradation of $\mathrm{MO}$ at just $2 \mathrm{~h}$, reaching complete degradation after $3 \mathrm{~h}$. This implies that ROS generation in microZnO and nanoZnO is upper than $50 \%$ compared to NS-ZnO. Besides ROS generation the oxygen content of $\mathrm{NS}-\mathrm{ZnO}$ is analyzed as $25.68 \% \mathrm{O}_{2}$. This oxygen content is 1.3 times higher than the theoretical one for the wurtzite structure of $\mathrm{ZnO}\left(19.66 \% \mathrm{O}_{2}\right)$. One of the possible causes for this fact is the presence of carbonate and hydroxyl groups from near-surface impurities detected by FTIR (showed in Fig. S1b). By contrast, oxygen content in nanoZnO is $19.85 \%$, close to the theoretical value (19.66\%). This approximation of oxygen content in nanoZnO to the theoretical value is due to a more crystalline structure than the NS-ZnO, that is, less intrinsic lattice defects and/or impurities such as $\mathrm{CO}_{2}$ and $\mathrm{H}_{2} \mathrm{O}$ that increase the oxygen content. To know the role of $\mathrm{Zn}^{2+}$ in the chemistry mechanism, a leaching assay is performed by ICP-OES. Fig. 4c shows the concentration of $\mathrm{Zn}^{2+}$ released for NS-ZnO and its comparison with the one obtained from micro and nanoZnO. It can be observed that micrometric $\mathrm{ZnO}$ presents the lowest concentration of $\mathrm{Zn}^{2+}$ ion in dissolution $\left(4.26 \mathrm{mg} \mathrm{L}^{-1}\right)$ followed by nanometric $\left(5.20 \mathrm{mg} \mathrm{L}^{-1}\right)$ and NS$\mathrm{ZnO}$ (5.45 $\left.\mathrm{mg} \mathrm{L}^{-1}\right)$, respectively. Moreover, the study of specific surface area displays significant increase between micrometric $\left(4.6 \mathrm{~m}^{2} \mathrm{~g}^{-1}\right)$ and NS-ZnO $\left(20.6 \mathrm{~m}^{2} \mathrm{~g}^{-1}\right)$ but smaller than nanoZnO $\left(23.9 \mathrm{~m}^{2} \mathrm{~g}^{-1}\right)$. Generally, in addition of the particle size, the specific surface area plays an important role in $\mathrm{Zn}^{2+}$ leaching. In our case, the NS-ZnO reaches lixiviation levels of the nanoZnO showing that the hierarchical organization of particles does not affect $\mathrm{Zn}^{2+}$ release. Moreover, thanks to sintering necks union between nanoparticles, the $\mathrm{Zn}^{2+}$ release 
E. de Lucas-Gil, P. Leret, M. Monte-Serrano, J.J. Reinosa, E. Enríquez, A. Del Campo, M. Cañete, J. Menéndez, J.F. Fernández, F. Rubio-Marcos, ZnO Nanoporous Spheres with Broad-Spectrum Antimicrobial Activity by Physicochemical Interactions, ACS Appl. Nano Mater. 1 (2018) $3214-3225$. doi:10.1021/acsanm.8b00402

does not lead to dissociation of $\mathrm{ZnO}$ spheres. The nanoparticles placement assumes that the highest $\mathrm{Zn}^{2+}$ release occurs in the external particles.

Once the chemical effects have been studied, the same procedure is performed with the physical effects. Since the electrostatic attraction is a contribution of physical interaction, a zeta $(\zeta)$ potential study of $\mathrm{ZnO}$ particles in solution is realized. Fig. $4 \mathbf{d}$ shows the zeta potential data of NS-ZnO with respect to bacteria and commercial references microZnO and nanoZnO. Arakha et al. report that zeta potential value of both Gram-positive (S. aureus) and Gram-negative (E. coli) bacteria for all tests is negative. ${ }^{49}$ As shown, the NS-ZnO provides a positive surface potential of $+32 \mathrm{mV}$ while starting micrometric $\mathrm{ZnO}$ (microZnO) has a negative surface potential of -10 $\mathrm{mV}$. The NS-ZnO behavior is surprisingly different than expected agreeing to the starting ZnO but according to their nanostructure organization. Analyzing the zeta potential of nanoZnO $(+29 \mathrm{mV})$ is shown that once again NS-ZnO behaves as nanometric material. Additionally, the positive surface potential of NS-ZnO is even higher than nanoZnO reference. The different particle charge is due to the crystallographic structure among other factors. The growth of microZnO particles occurs preferentially in the (0001) crystallographic direction, generating hexagonal prisms (Fig. S4). Therefore, the main surface of $\mathrm{ZnO}$ microparticle corresponds to a crystallographic direction perpendicular to the one of preferential growth (0001). The feature of such perpendicular crystallographic direction is that is composed of alternating $\mathrm{Zn}^{2+}$ and $\mathrm{O}^{2-}$ planes. The surface charge balance in microZnO provides a negative charge. By contrast, in nanoparticle cases, the lower growth of the particle causes surface finishing in (0001) planes which modify the charge balance and the surface became positively charged. The polarity change of particles versus the size reduction is in agreement with previous experiments in oxides with hexagonal structure..$^{50}$ 
E. de Lucas-Gil, P. Leret, M. Monte-Serrano, J.J. Reinosa, E. Enríquez, A. Del Campo, M. Cañete, J. Menéndez, J.F. Fernández, F. Rubio-Marcos, ZnO Nanoporous Spheres with Broad-Spectrum Antimicrobial Activity by Physicochemical Interactions, ACS Appl. Nano Mater. 1 (2018) $3214-3225$. doi:10.1021/acsanm.8b00402.
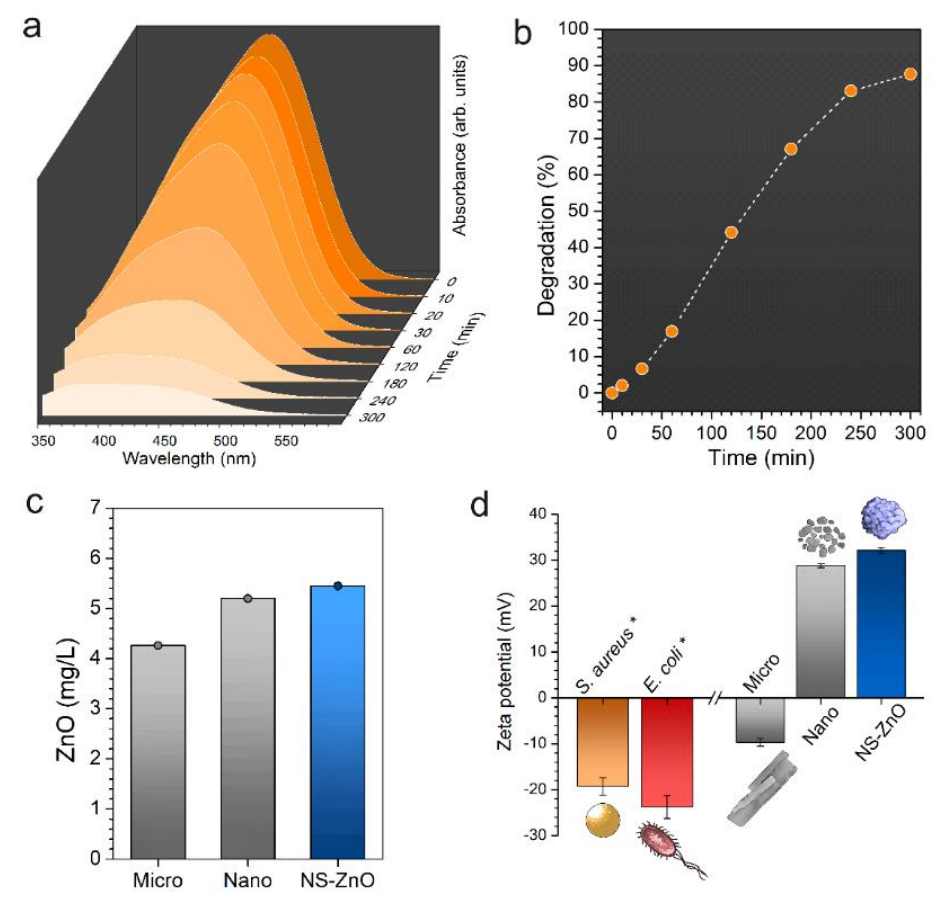

Figure 4 | Relevance of chemical and physical mechanisms in antimicrobial activity of nanostructured ZnO. Evolution of methyl orange (MO) maximum absorption band (a) and photocatalytic degradation as a function of time (b) to detect ROS in obtained $\mathrm{ZnO}$. Chemical analysis of $\mathrm{Zn}^{2+}$ released in distilled water after $24 \mathrm{~h}$ (c) for micro and nanoZnO and NS-ZnO. Zeta potential comparison (d) of bacteria, commercial references (micro and nanoZnO) and NS-ZnO. Zeta potential data are shown with mean values and standard error bars. *Zeta potential data of S. aureus and E. coli are obtained from Arakha et al..$^{49}$

How the "charged interfaces" are generated into the hierarchical structures. To better understand this behavior, a complete structural study of NS-ZnO is realized. Carefully observing the TEM micrographs, we detect that nanoparticles are joined by sintering necks (Fig. 5a) that form grain boundary between nanoparticles. In turn, each nanoparticle has different crystallographic orientation, which creates a potential barrier at the grain boundary. The energy band gap study is realized by ultraviolet-visible (UV-vis) spectroscopy using the total reflectance, i.e. direct and diffuse. After obtaining total reflectance spectra (Fig. S8a) of NS-ZnO and micro and nanoZnO reference, in order to correct the reflection measures, the Kubelka Munk approximation is used. Then, to obtain the band gap from the Kubelka Munk function is necessary to extrapolate the absorption to $a=0$ in Tauc's curves (Fig. S8b). The extrapolation of Tauc's curves (Fig. $\mathbf{5 b}$ ) displays band gap changes among the $\mathrm{ZnO}$ cluster and commercial references. As shown in Fig. $\mathbf{5 b}$ the lowest band gap energy corresponds to $\mathrm{NS}-\mathrm{ZnO}(3.242 \mathrm{eV})$ while microZnO reference has an intermediate value (3.256 $\mathrm{eV})$ and nanoZnO reference takes the highest value $(3.267 \mathrm{eV})$. The band gap increasing with the reduction of particle size is in agreement with the quantum confinement effects that it is also modulated by the 
E. de Lucas-Gil, P. Leret, M. Monte-Serrano, J.J. Reinosa, E. Enríquez, A. Del Campo, M. Cañete, J. Menéndez, J.F. Fernández, F. Rubio-Marcos, ZnO Nanoporous Spheres with Broad-Spectrum Antimicrobial Activity by Physicochemical Interactions, ACS Appl. Nano Mater. 1 (2018) $3214-3225$. doi:10.1021/acsanm.8b00402

agglomeration state. In nanoparticle agglomerates, there is a particle-particle phonon partial transmission, which produces a larger relaxation of the momentum conservation than in single isolated nanoparticles..$^{51}$ So, the lowest band gap value for the NS- $\mathrm{ZnO}$ respect to $\mathrm{ZnO}$ microparticles and nanoparticles band gap values is a consequence of the agglomerated nanoparticles in the nanostructure organization.

Raman spectroscopy is also employed to characterize structurally the NS- $\mathrm{ZnO}$ and micro and nanoZnO references. The Fig. $\mathbf{5 c}$ shows that principal modes in Raman spectra have a similar behavior. The most relevant differences are localized at $477 \mathrm{~cm}^{-1}$ and $583 \mathrm{~cm}^{-1}$. The first peak at $477 \mathrm{~cm}^{-1}$ is associated to surface optical phonon modes. ${ }^{52}$ Nanoparticles have a significant number of surface atoms so that, a higher occurrence of surface optical phonon is expected. The Raman spectrum of nanoZnO confirms that this mode is extant in nanoparticles. Surprisingly, the surface optical phonon mode is also present in NS-ZnO, having a higher intensity than nanoZnO Raman spectrum. The high intensity of the surface optical phonon is an indication of the event's occurrence related the photon energy transfer to surface polarizable bonds at $\mathrm{ZnO}$. This higher occurrence of surface optical phonon mode, when compared with the main Raman mode E2high at $441 \mathrm{~cm}-1$ in NS- $\mathrm{ZnO}$, is a mark that the particle size is not the only parameter that enhances such energy transfer. Raman peak at $583 \mathrm{~cm}^{-1}$ is fitted in two Gaussian peaks: $A_{1}(L O)$ and $E_{1}(L O)$. These Raman modes are associated with intrinsic lattice defects. ${ }^{53,54} \mathrm{So}$, it is concluded that in addition of enhancement of surface optical phonon a large amount of intrinsic lattice defects is present in NS-ZnO.

In addition, X-ray photoelectron spectroscopy (XPS) is used to determine the surface composition and chemical states of sample and references (micro and nanoZnO). The Zn 2p spectra (Fig. S9a) show two peaks identified as $\mathrm{Zn} 2 \mathrm{p}_{3 / 2}$ and $\mathrm{Zn} 2 \mathrm{p}_{1 / 2}$ lines, respectively. Moreover, the binding energy difference between these two peaks $(23.1 \mathrm{eV})$ confirms that $\mathrm{Zn}$ element exists mainly in the $\mathrm{Zn}^{2+}$ form in all samples. ${ }^{55}$ At the same time, the $\mathrm{O} 1 \mathrm{~s}$ region (Fig. S9b) displays an asymmetric peak fitted with three Gaussian curves that are attributed to the $\mathrm{O}^{2-}$ ions which are surrounded by zinc atoms, in the oxygen-deficient region within the $\mathrm{ZnO}$ matrix and to chemisorbed oxygen, respectively. ${ }^{56-59}$ The relative areas of Gaussian curves indicate a different behavior between microparticles and nanoparticles (Fig. S9c). In the microparticles case, this study confirms us that the surface structure is a nearly perfect crystal, i.e. less oxygen deficiency and more oxygen on the wurtzite structure. Conversely, the nanoparticles show a greater surface oxygen deficiency so that they do not allow generating 
E. de Lucas-Gil, P. Leret, M. Monte-Serrano, J.J. Reinosa, E. Enríquez, A. Del Campo, M. Cañete, J. Menéndez, J.F. Fernández, F. Rubio-Marcos, ZnO Nanoporous Spheres with Broad-Spectrum Antimicrobial Activity by Physicochemical Interactions, ACS Appl. Nano Mater. 1 (2018) $3214-3225$. doi:10.1021/acsanm.8b00402.

complete crystalline structures. Respect to NS-ZnO, once again the surface defect behavior resembles nanoparticles. This fact ratifies that the number of defects, mainly oxygen deficiency, are located on nanoparticle or nanostructured surfaces. Concurrently, the chemisorbed oxygen may explain the increase in oxygen content for NS-ZnO with respect to theoretical one. Furthermore, the higher presence of structural defects leads to engender Schottky Barrier (SB) at the grain boundary in NS-ZnO clusters (Fig. 4d). The presence of SBs has previously been shown in $\mathrm{ZnO}$ microparticles. ${ }^{44}$ However, Schottky Barriers in $\mathrm{ZnO}$ nanoparticles have never been observed before. Only evidence of Schottky formation in the basal plane of the $\mathrm{ZnO}$ thin film is provided. ${ }^{60}$ Note that the union between $\mathrm{ZnO}$ semiconductor nanocrystals occurs under conditions such that the orientation of the crystalline planes is imperfect. As consequence of the incipient sintering necks between $\mathrm{ZnO}$ nanoparticles to form the nanoporous sphere structure a large number of interfaces or grain boundaries is developed. These interfaces blocked the carrier's mobility producing changes in the zeta potential, as shown in Fig. 4d. The lower presence of ROS determined in the photocatalysis experiments (Fig. $\mathbf{4 b}$ ) is evidence of carrier retention within the nanomaterial. The existence of potential or Schottky barriers, and therefore, the accumulation of charge is a limitation for the charge to reach the surface.

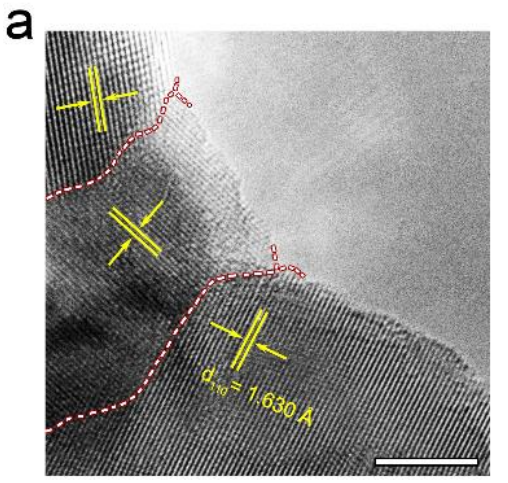

d
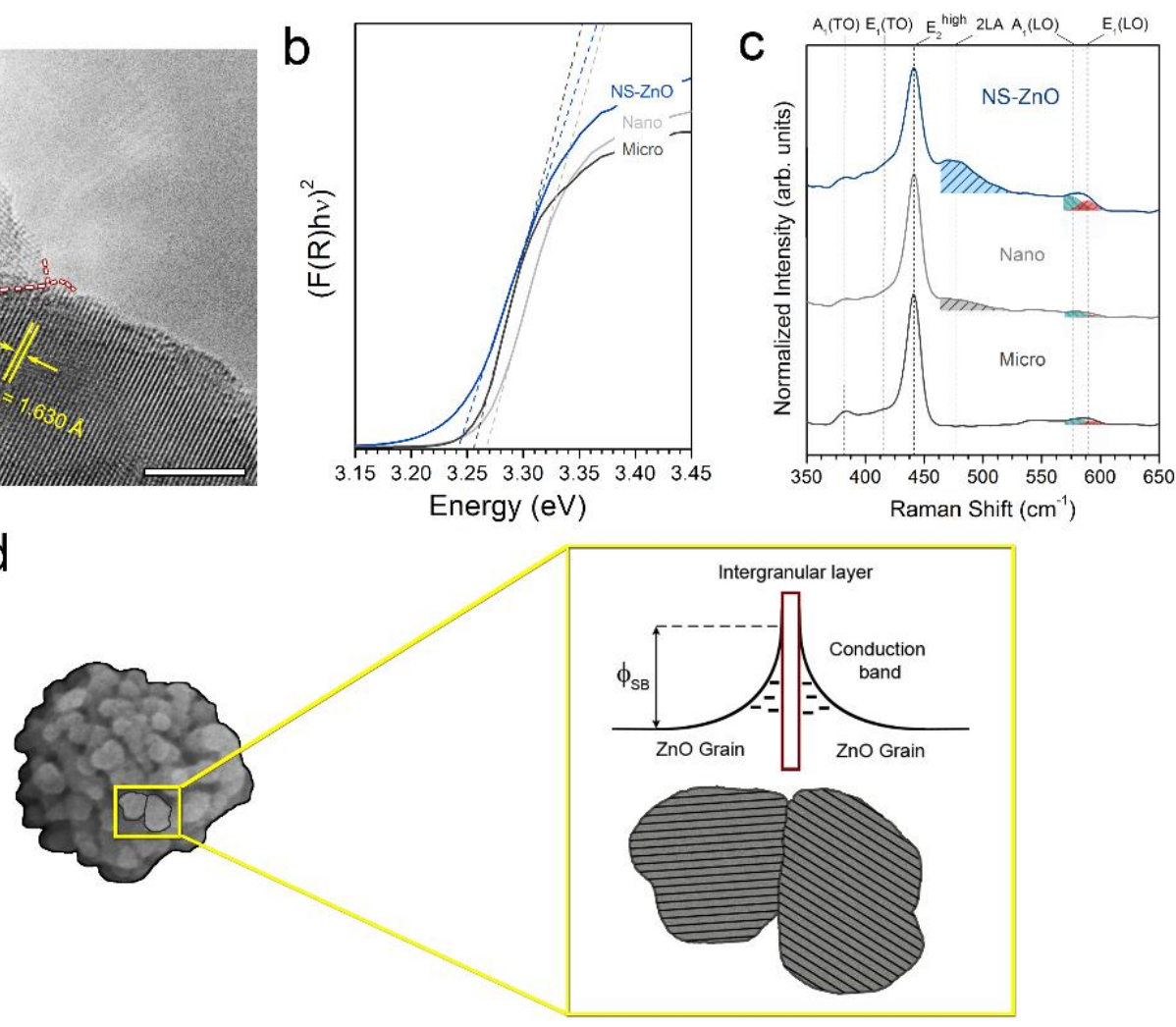
E. de Lucas-Gil, P. Leret, M. Monte-Serrano, J.J. Reinosa, E. Enríquez, A. Del Campo, M. Cañete, J. Menéndez, J.F. Fernández, F. Rubio-Marcos, ZnO Nanoporous Spheres with Broad-Spectrum Antimicrobial Activity by Physicochemical Interactions, ACS Appl. Nano Mater. 1 (2018) $3214-3225$. doi:10.1021/acsanm.8b00402.

Figure 5 Importance of electronic structure changes in positive electric potential. In TEM micrograph (a) are observed three particles linked by sintering necks with different crystallographic orientation and two potential barriers (for the sake of clarity marked by a red dash line). Scale bar is $5 \mathrm{~nm}$. Panel $\mathbf{b}$ shows the band gap of NS-ZnO (blue) compared with microZnO (dark gray) and nanoZnO (light gray) references. The striped areas of the Raman spectrum (c) display change in principal bands for NS-ZnO (blue) with respect to micro (dark gray) and nanoZnO (light gray). A schematic mechanism is proposed for the appearance of a potential Schottky Barrier ( $\left.\Phi_{\mathrm{SB}}\right)$ at the grain boundary (d).

How do $\mathrm{ZnO}$ nanoporous spheres act against microorganisms? The physical interaction importance is shown in the micrographs of both Gram-negative (Fig. 3c) and Gram-positive (Fig. 3f) bacteria. The strong attraction of NS-ZnO may be caused by electrostatic forces. Some authors report that the interaction between bacteria and $\mathrm{ZnO}$ particles is due to the negative charge of the bacterial surface at biological $\mathrm{pH}$ values and positive charge of $\mathrm{ZnO} .5,61,62$ The zeta potential measurements of NS-ZnO confirm that particle surface is positively charged (Fig. 4d) due to the particle size that produces a balance between the crystalline terminations and the presence of defects in the structure..$^{50} \mathrm{~A}$ surface defective structure in oxygen provides the polarity change of the $\mathrm{ZnO}$ as confirmed by XPS. As a result, opposite charges between bacteria and NS-ZnO generates an attraction that becomes a strong bond with cell surface producing membrane envelope damage.

Moreover, the appearance of Schottky barriers at the interfaces between different crystallographic orientations (see Fig. 5d) is a consequence of the nanostructured organization of NS-ZnO. The nanostructure organization of the NS-ZnO clusters proportionates a high number of interfaces in which the carrier accumulates. The Raman spectroscopy proves surface phonon enhancement in NS-ZnO that could be related to the appearance of a local electric field promoted by such accumulation of the carrier at the Schottky barriers. Moreover, the agglomerate structure of NS-ZnO allows increasing accumulate surface charge without detachment of isolated $\mathrm{ZnO}$ nanoparticles. The Schottky barrier also limits the ability of the carrier to reach the surface of the crystalline structure and to promote the appearance of ROS. Our result confirms that NS-ZnO is highly effective in antimicrobial activity, but reduces the appearance of ROS that negatively affect other living organism and chemical. Thus, the present approach results highly interesting because it could lead to new antimicrobial inorganic without the deleterious damage produced by ROS species as the one pursued in dermatology applications.

In this scenario, the chemical interaction also has an important impact on antimicrobial activity due to the presence of ROS (Fig. 4a-b) and $\mathrm{Zn}^{2+}$ cations (Fig. 4c-d) against microorganisms in dissolution. Therefore, an 
E. de Lucas-Gil, P. Leret, M. Monte-Serrano, J.J. Reinosa, E. Enríquez, A. Del Campo, M. Cañete, J. Menéndez, J.F. Fernández, F. Rubio-Marcos, ZnO Nanoporous Spheres with Broad-Spectrum Antimicrobial Activity by Physicochemical Interactions, ACS Appl. Nano Mater. 1 (2018) $3214-3225$. doi:10.1021/acsanm.8b00402.

antimicrobial mechanism of NS-ZnO against $E$. coli is proposed in Fig. 6 (The reader can find more information about the proposed antimicrobial mechanism for S. aureus in Figure S10 of the Supporting Information). This comprises a combination of physical and chemical interactions. First step (Fig. 6.1), electrostatic forces come into play between the negative charge of bacteria and the positive charge of NS-ZnO. The adhesion of the hierarchical clusters to the bacterial surface improves the action of NS-ZnO close to the bacterial membrane. In the second step (Fig. 6.2), $\mathrm{ZnO}$ generates chemical reagents, both $\mathrm{Zn}^{2+}$ cations and ROS in a minor amount. Due to the negative charge membrane, the $\mathrm{Zn}^{2+}$ released can penetrate easily into the cell causing cytotoxic effects. ${ }^{36}$ As shown in this article, not only nanoparticles provide $\mathrm{Zn}^{2+}$ cations leaching from the crystal structure. In our case, the NS-ZnO supplies the $\mathrm{Zn}^{2+}$ cations thanks to its high specific surface area. Moreover, a nanoparticles drawback is the penetration into the living bodies due to their small size. Thus, the hierarchical agglomerate organization of NS-ZnO avoids the presence of isolated nanoparticles that can eventually penetrate in the organisms. The developed NS-ZnO possesses a medium size that behaves as sub-microparticles and therefore its use becomes more secure. Respect to reactive oxygen species (ROS), its principal role is to cause cellular oxidative stress. However, several species are generated and most of them cannot penetrate the cell because of its negative charge. While negative charge ROS remain in direct contact with the outer surface of the bacteria, the hydrogen peroxide $\left(\mathrm{H}_{2} \mathrm{O}_{2}\right)$ penetrates into the cell. ${ }^{24}$ Negative ROS at the outer surface of the cell could neutralize the effectiveness of $\mathrm{Zn}^{2+}$. Besides, the proximity of $\mathrm{ZnO}$ to the bacteria and the membrane damage, which are generated by electrostatic forces, and the reduction of ROS facilitate the entry of $\mathrm{Zn}^{2+}$ cations inside the cell. All this leads to cellular damage like blebs, wrinkles, etc.... that causes shrinkage of bacterial cells, leakage of intracellular components and eventually death (Fig. 6.3). Finally, the symbiosis that occurs between physical and chemical interactions approaching the distances microorganism- $\mathrm{ZnO}$, resulting in improved the antimicrobial activity. Moreover, NS-ZnO keeps its hierarchical structure during the process against microorganisms (Fig. 3c, f), fulfilling its commitment to safer design preventing deposition in the alveolar region or penetration the first skin layers. 
E. de Lucas-Gil, P. Leret, M. Monte-Serrano, J.J. Reinosa, E. Enríquez, A. Del Campo, M. Cañete, J. Menéndez, J.F. Fernández, F. Rubio-Marcos, ZnO Nanoporous Spheres with Broad-Spectrum Antimicrobial Activity by Physicochemical Interactions, ACS Appl. Nano Mater. 1 (2018) $3214-3225$. doi:10.1021/acsanm.8b00402

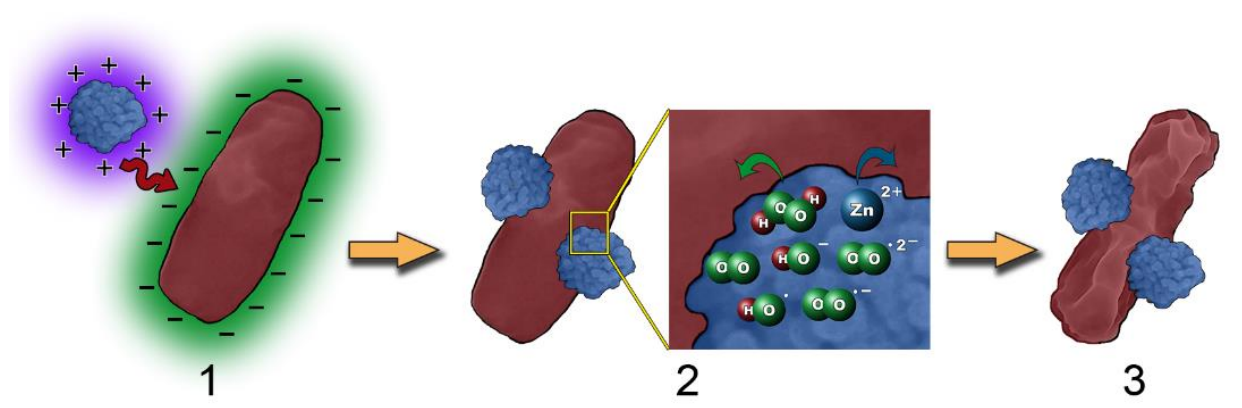

Figure 6 | Mechanism of NS-ZnO against microorganisms. The panel shows a generic mechanism of action against microorganisms that can be divided into three steps. (1) Electrostatic attraction between bacteria membrane and $\mathrm{ZnO}$ nanoporous spheres. Approximate once the $\mathrm{ZnO}$, the next step (2) is the release of $\mathrm{Zn}^{2+}$ from NS- $\mathrm{ZnO}$ to bacteria. The step (3) is the collapse of the bacteria due to physical and chemical damage suffers.

The selectivity of ZnO nanoporous sphere: are they cytotoxic to human cells? To carry out this study, a cytotoxicity assay is performed on tumor epithelial cell line HeLa. The HeLa cells were incubated with a 0.2 $\mathrm{mg} / \mathrm{mL}$ concentration of $\mathrm{ZnO}$ for $24 \mathrm{~h}$. After that, cell viability was determined by the (3-(4,5-dimethylthiazol2-yl)-2,5-diphenyltetrazolium bromide, called as MTT assay. In order to compare the potential cytotoxicity, the assay was performed with commercial reference microZnO (Fig. 7a), nanoZnO (Fig. 7b) and NS-ZnO (Fig. 7c). The cell survival was determined from the $540 \mathrm{~nm}$ absorption band is measured in each assay. As shown in Fig. 7 d, the microZnO does not have cytotoxicity activity $(100 \%)$ due to its micrometric size. On the other hand, the behavior of nanometric samples differs from the micrometer $\mathrm{ZnO}$. The nanoZnO induces a greater decrease in the living cell population $(72 \%)$ than NS-ZnO $(81 \%)$ in the culture medium. Taking into account the abovementioned points, our results show a selective action of $\mathrm{ZnO}$ spheres being potentially low-cytotoxic to human cells and good antimicrobial agents against microorganisms. To sum up, note that nanometric particles (nanoZnO and NS-ZnO) show greater cytotoxicity. By contrast, microZnO generates more ROS than NS-ZnO (Fig. S7) and its cytotoxicity is null in the studied concentration (Fig. 7). This fact indicates that cytotoxicity is not only caused by the ROS generation. Therefore, cytotoxicity of $\mathrm{ZnO}$ particles is a compromise between particle size and ROS generation. 
E. de Lucas-Gil, P. Leret, M. Monte-Serrano, J.J. Reinosa, E. Enríquez, A. Del Campo, M. Cañete, J. Menéndez, J.F. Fernández, F. Rubio-Marcos, ZnO Nanoporous Spheres with Broad-Spectrum Antimicrobial Activity by Physicochemical Interactions, ACS Appl. Nano Mater. 1 (2018) $3214-3225$. doi:10.1021/acsanm.8b00402.
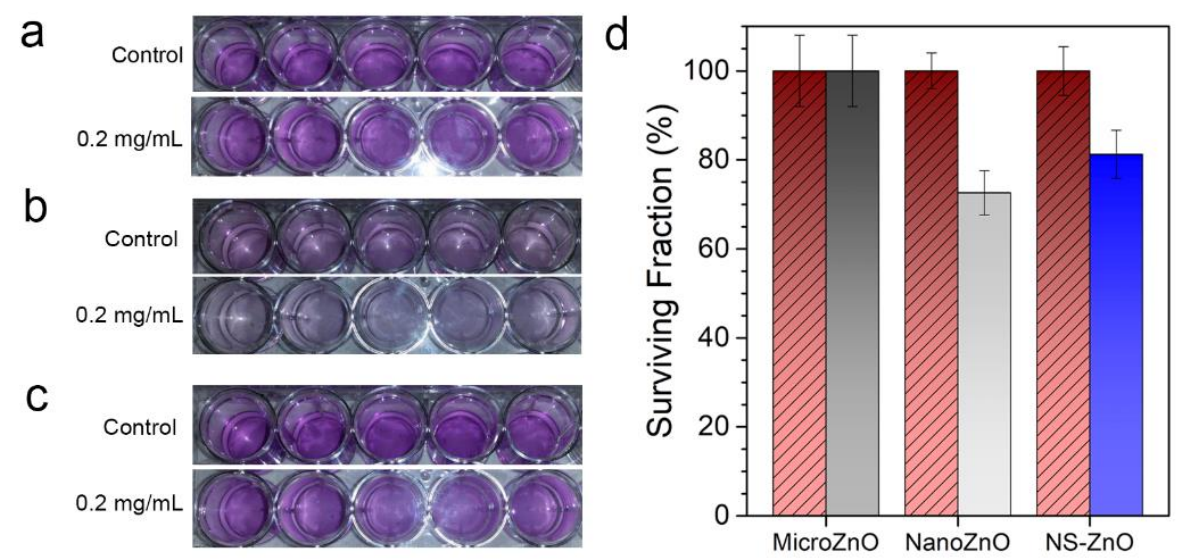

Figure 7 I Evaluation of cytotoxicity. MTT assay $24 \mathrm{~h}$ after treatments of microZnO (a), nanoZnO (b) and NS-ZnO (c). Survival of HeLa cells incubated with $0.2 \mathrm{mg} / \mathrm{mL}$ (d).

\section{Conclusions}

To conclude, we are able to create nanostructured $\mathrm{ZnO}$ clusters by soft chemistry, which develop excellent antimicrobial properties. The nanoparticle organization into hierarchical clusters allows preserving nanometric properties in submicron structures, such as a specific surface area. Here, interestingly, it is noted that the $\mathrm{ZnO}$ clusters simultaneously possess a higher antibacterial and antifungal activity and a low cytotoxicity as compared with a commercial nanoZnO. More importantly, the action mechanism is mainly based on the synergistic effect of physical and chemical interactions between microorganism and $\mathrm{ZnO}$, which greatly benefit the antimicrobial properties. Specifically, among physical interactions highlight electrostatic forces that approximate distances between microorganism and $\mathrm{ZnO}$ clusters. This closeness between them enables better chemical interaction through $\mathrm{Zn}^{2+}$ cations leached by the high specific surface area of $\mathrm{ZnO}$ clusters. However, antimicrobial efficacy based on $\mathrm{Zn}^{2+}$ cations is not possible if it is not enhanced by the participation of ROS and ZnO-microbe attraction by electrostatic forces. The union of these two interactions (chemical and physical) synergistically leads to microorganism death. It is also worth highlighting the $\mathrm{ZnO}$ clusters robustness because they do not lose their hierarchical structure during their action against microorganisms. For all that, nanostructured $\mathrm{ZnO}$ in the form of nanoporous spheres is a broad-spectrum, low-cytotoxicity antimicrobial inorganic material for many applications such as textile (e.g. antimicrobial shoe insoles), cosmetic (e.g. preservative) or hospital/pharma industries (e.g. sterile dressing).

\section{Materials and Methods}


E. de Lucas-Gil, P. Leret, M. Monte-Serrano, J.J. Reinosa, E. Enríquez, A. Del Campo, M. Cañete, J. Menéndez, J.F. Fernández, F. Rubio-Marcos, ZnO Nanoporous Spheres with Broad-Spectrum Antimicrobial Activity by Physicochemical Interactions, ACS Appl. Nano Mater. 1 (2018) 3214-3225. doi:10.1021/acsanm.8b00402.

Sample preparation. All the chemicals were directly used without further purification. To start the procedure, a suspension of 6 wt.\% micrometric zinc oxide ( $\mathrm{ZnO}$, Asturiana de Cinc S.A.) in 3.6 moles of glycerol (Sigma-Aldrich) is prepared and homogenized. Subsequently, 3.6 moles of urea $\left(\mathrm{CO}\left(\mathrm{NH}_{2}\right)_{2}\right.$, Sigma-Aldrich) were added to the suspension under stirring at room temperature. The reaction was heated in a silicone bath at $120-140^{\circ} \mathrm{C}$ and stirred at $300 \mathrm{rpm}$ for $4 \mathrm{~h}$. The role of urea is to provide the reaction with ammonia and $\mathrm{CO}_{2}$, from its decomposition. The presence of ammonia generates a basic $\mathrm{pH}$ during the reaction. After naturally cooling the precipitate was isolated by filtration and washed with water and ethanol several times to remove impurities. The white powder was dried at $80^{\circ} \mathrm{C}$ for $24 \mathrm{~h}$. At the end, the product was thermally treated at $500^{\circ} \mathrm{C}$ for a short time, $5 \mathrm{~min}$, in the air.

Reference products. To compare some properties of synthesized NS-ZnO, two commercial references of $\mathrm{ZnO}$ were chosen based on their size. Micrometric $\mathrm{ZnO}$ (microZnO), used in the reaction, was acquired from Asturiana de Cinc S.A. (Spain). Respect to nanometric $\mathrm{ZnO}$ (nanoZnO) was purchased from Evonik Industries (Germany). Both products were thermally treated at $500^{\circ} \mathrm{C}$ to keep annealing conditions of NS-ZnO.

Structural characterization. Crystalline phases were characterized by X-ray diffraction (XRD, X'Pert PRO Theta/2theta of Panalytical, $\mathrm{Cu} \mathrm{K} \mathrm{K}_{\alpha}$ radiation, PANalytical, The Netherlands), using $\mathrm{CuK}_{\alpha}$ radiation. The patterns were recorded over the angular range $20-70^{\circ}(2 \theta)$ with a step size of $0.0334^{\circ}$ and a time per step of 100 seconds, using $\mathrm{Cu} \mathrm{K}_{\alpha}$ radiation $(\lambda=0.154056$ $\mathrm{nm}$ ) with working voltage and current of $40 \mathrm{kV}$ and $100 \mathrm{~mA}$, respectively. The crystallite size is calculated from the full width at half-maximum (FWHM) of the diffraction peaks by using Scherrer's equation. The composition of the sample was also measured by Fourier Transform Infrared (FT-IR, Perkin Elmer Spectrum 100) with a wavenumber range from $400-4000$ $\mathrm{cm}^{-1}$. X-ray absorption near-edge structure spectroscopy (XANES) measurements were carried out at Zn K-edge at the Spanish CRG beamline BM25A (SpLine) at the European Synchrotron (ESRF), France. The XANES experiment was performed in transmission mode to determine the oxidation state of $\mathrm{Zn}$ in samples. Final spectra represent an average of three X-ray absorption (XAS) scans. The X-ray absorption data were analysed using ATHENA software. The surface area and the adsorption/desorption isotherm of the sample was determined with a Micromeritics ASAP-2020 analyzer with $\mathrm{N}_{2}$ as the adsorbent at $-196^{\circ} \mathrm{C}$. The frequency modes of samples were characterized by Confocal Raman Microscopy (CRM, Witec alpha-300R). Raman spectra were obtained using a frequency-doubled Nd-YAG laser operating at $532 \mathrm{~nm}$ and a $100 \mathrm{X}$ objective lens (numerical aperture $=0.9$ ). The incident laser power was $20 \mathrm{~mW}$. The surface composition was performed using an X-ray Photoelectron Spectrometer (XPS, K-Alpha, Thermo Scientific). Prior to analysis, the samples were cleaned by ion-bombardment with an $\mathrm{Ar}^{+}$beam $(2 \mathrm{kV})$ for $5 \mathrm{~min}$. It utilizes a monochromated $\mathrm{Al} \mathrm{Ka}(1486.6 \mathrm{eV})$ source running at a voltage of $12 \mathrm{KV}$ with a pass energy of $40 \mathrm{eV}$ was used for high-resolution region scans and $200 \mathrm{eV}$ for survey scans; finally, for charge correction a 1 point scale with the C 1s peak shifted to $285.0 \mathrm{eV}$ was used. The Energy band gap was analyzed using ultraviolet-visible spectroscopy (UV-Vis spectrophotometer, Pelkin Elmer-Lambda 950).

Electron Microscopy. The morphology of the powder was evaluated using primary electron images of field emission scanning electron microscopy (FE-SEM, Hitachi S-4700). The composition of the powders was estimated using Energy Dispersive Spectroscopy, EDS. Moreover, an image processing and analysis program (Leica Qwin, Leica Microsystems Ltd, Cambridge, England) were used to determine the average particle size from FE-SEM micrographs. Under conditions always is considered more than 200 particles in each measurement. In the specific case of NS-ZnO particles with bacteria evaluation by SEM, the samples were prepared in distilled water. Then, the suspension was dispersed for 5 min by ultrasound. After that, an aliquot is deposited in a sample holder for analysis and then the solvent was removed. We have tried to minimize the effects of particle agglomeration due to the drying of the solvent by choosing a working area away from the drop edge. To further understand the detailed morphology and crystal structure of the powder, the sample was evaluated using a 
E. de Lucas-Gil, P. Leret, M. Monte-Serrano, J.J. Reinosa, E. Enríquez, A. Del Campo, M. Cañete, J. Menéndez, J.F. Fernández, F. Rubio-Marcos, ZnO Nanoporous Spheres with Broad-Spectrum Antimicrobial Activity by Physicochemical Interactions, ACS Appl. Nano Mater. 1 (2018) $3214-3225$. doi:10.1021/acsanm.8b00402.

JEOL 2100F transmission electron microscope (TEM/HR-TEM) operating at $200 \mathrm{KV}$ and equipped with a field emission electron gun providing a point resolution of $0.19 \mathrm{~nm}$. For TEM sample preparation, the particles were carefully suspended in ethanol and dispersed using an ultra-sonication bath for 10 minutes. The suspension was dropped on a copper TEM grid with carbon film support. The particles were kept at the grid after evaporation of ethanol.

Textural characterization. The specific surface area was determined by the BET method (SSA, Monosorb Surface Area Analyser MS-13, Quantachrome).

Potential surface characterization. The zeta potential was studied using a zeta analyzer (ZetasizerNano NS, Malvern S, UK). For sample preparation, $\mathrm{ZnO}$ was added in distilled water. The suspension was stirred under ultrasound and adjusted to $\mathrm{pH} 7.4$.

UV Photocatalytic degradation. The photocatalytic activity of synthesized NS-ZnO was studied by the degradation of a typical organic dye, methyl orange $\left(\mathrm{MO}, \mathrm{C}_{14} \mathrm{H}_{14} \mathrm{~N}_{3} \mathrm{NaO}_{3} \mathrm{~S}\right)$, under UV light irradiation at ambient temperature in air with magnetic stirring. A $0.05 \mathrm{mM}$ solution of $\mathrm{MO}$ was prepared in deionized water. Subsequently, $100 \mathrm{mg} \mathrm{\textrm {L } ^ { - 1 }}$ of $\mathrm{ZnO}$ powder was added to the MO solution. The mixture was magnetically stirred with a magnetic bar for 15 min in the dark, to allow adsorption equilibrium. After that, the suspension was irradiated with UV light $(24 \mathrm{~W})$ and aliquots are collected from the above suspension at different time intervals $(10,20,30,60,120,180,240,300 \mathrm{~min})$. The aliquots were centrifuged at high speed $(6000 \mathrm{rpm})$ for $30 \mathrm{~min}$. The obtained samples were then analyzed using ultraviolet-visible spectroscopy (UV-Vis spectrophotometer, Pelkin Elmer-Lambda 950) by recording variations in absorbance at a wavelength of $463 \mathrm{~nm}$. The degradation percentage, $\mathrm{D}(\%)$, was calculated according to Beer-Lambert law as in Eq. 1:

$$
\mathrm{D}(\%)=\frac{\mathrm{C}_{0}-\mathrm{C}}{\mathrm{C}_{0}} \times 100=\frac{\mathrm{A}_{0}-\mathrm{A}}{\mathrm{A}_{0}} \times 100
$$

where $\mathrm{C}_{0}$ is the initial concentration of $\mathrm{MO}$ solution and $\mathrm{C}$ is the concentration after photodegradation. $\mathrm{A}_{0}$ and $\mathrm{A}$ are the absorbances of samples at the beginning time $\left(t_{0}\right)$ of irradiation and at time $t$, respectively.

Chemical Analysis. $\mathrm{Zn}^{2+}$ released was determined by inductively coupled plasma optical emission spectrometry (ICP-OES, Iris Advantage, Termo Jarrel Ash). For sample preparation, 10g L-1 of ZnO (NS-and references) was added in $25 \mathrm{~mL}$ of distilled water. The suspension was stirred under ultrasound $5 \mathrm{~min}$ and it was allowed to stand for $24 \mathrm{~h}$. After that, the suspension was centrifuged and decanted obtaining a colorless dissolution. Data are expressed in concentration in oxide form. Oxygen content was performed by the elemental $\mathrm{N}_{2} / \mathrm{O}_{2}$ analyzer (LECO TC-436, LECO Corporation, St. Joseph, Michigan) based on the inert gas fusion technique. First, the sample was purged with inert atmosphere to remove passively adsorbed gases. Then, the sample was combusted in the absence of oxygen and the extracted gases were detected by infrared spectroscopy (IR). Finally, the oxygen content is calculated from resulting carbon dioxide $\left(\mathrm{CO}_{2}\right)$ detected.

Antifungal activity tests. As for antifungal activity, the pathogenic fungus Aspergillus niger (CECT 2807) was used for testing. Antifungal tests were performed by the Kirby-Bauer method (or agar diffusion method) with some modifications. The agar culture medium contains: $\mathrm{NaNO}_{3} 2 \mathrm{~g}, \mathrm{KH}_{2} \mathrm{PO}_{4} 0.7 \mathrm{~g}, \mathrm{~K}_{2} \mathrm{HPO}_{4} 0.3 \mathrm{~g}, \mathrm{KCl} 0.5 \mathrm{~g}, \mathrm{MgSO}_{4} \cdot 7 \mathrm{H}_{2} \mathrm{O} 0.5 \mathrm{~g}, \mathrm{FeSO}_{4} \cdot 7 \mathrm{H}_{2} \mathrm{O}$ $0.01 \mathrm{~g}$, Agar $20 \mathrm{~g}$, Glucose $30 \mathrm{~g}$ and Distilled water $1 \mathrm{~L}$. In a standard process, the A. niger culture of an initial concentration of $3 \times 10^{7}$ spores $\mathrm{mL}^{-1}$ was inoculated on the surface of Petri dishes. After, filter paper disks were impregnated with a suspension of $0.01 \% \mathrm{ZnO}$. The Petri dishes with the inoculums were then incubated at $37^{\circ} \mathrm{C}$ for 3 days. The effectiveness of $\mathrm{ZnO}$ samples was evaluated by measuring the inhibition diameter of the grown fungus in the Petri dish. To compare the results with other particle sizes, two references are used (microZnO and nanoZnO). All tests were performed in triplicate and the values were expressed in millimeters. 
E. de Lucas-Gil, P. Leret, M. Monte-Serrano, J.J. Reinosa, E. Enríquez, A. Del Campo, M. Cañete, J. Menéndez, J.F. Fernández, F. Rubio-Marcos, ZnO Nanoporous Spheres with Broad-Spectrum Antimicrobial Activity by Physicochemical Interactions, ACS Appl. Nano Mater. 1 (2018) $3214-3225$. doi:10.1021/acsanm.8b00402.

Antibacterial activity test. To test the antibacterial activity, the microbial growth of two kinds of bacteria, Escherichia coli (CECT 516, ATCC 8739) and Staphylococcus aureus (CECT 240, ATCC 6538P), was used for testing. The Macrodilution method from the National Committee of Clinical Laboratory Standards (NCCLS) was performed with some modifications. According to this methodology, 3 ppm of $\mathrm{ZnO}$ was introduced in test tubes containing buffered peptone water $(\mathrm{PW})$ at $\mathrm{pH}$

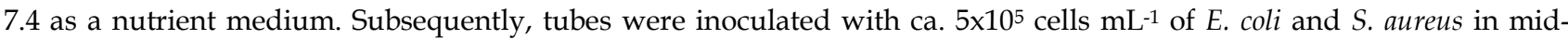
exponential phase and incubated at $37^{\circ} \mathrm{C}$ for $24 \mathrm{~h}$. Bacterial counts were enumerated by sub-cultivation on TSA plates. All tests were performed in duplicate and the values were expressed in colony forming units per mL of suspension. To know the product efficacy, the value of antimicrobial activity (R) was calculated (eq. 2):

$$
\mathrm{R}=\log (\mathrm{C} / \mathrm{I})-\log (\mathrm{P} / \mathrm{I})=\log (\mathrm{C} / \mathrm{P})
$$

where I is the average of the number of viable cells of bacteria just incubated ( $\left.\mathrm{t}_{0}\right), \mathrm{C}$ after $24 \mathrm{~h}$ of incubation (control) and $\mathrm{P}$ after $24 \mathrm{~h}$ of incubation treated with the product. In addition, two references with different particle sizes, micro and nanoZnO, were used to compare the results with $\mathrm{NS}-\mathrm{ZnO}$.

Cytotoxicity test. For this study, the human cells used are the tumor epithelial cell line HeLa (cervix adenocarcinoma). HeLa cells were grown in Dulbecco's modified Eagle's medium (DMEM) supplemented with 10\% (v/v) fetal bovine serum (FBS), 50 units $/ \mathrm{mL}$ penicillin and $50 \mu \mathrm{g} / \mathrm{mL}$ streptomycin. Cell cultures were performed in a $5 \% \mathrm{CO}_{2}$ atmosphere at $37{ }^{\circ} \mathrm{C}$ and maintained in a Steri-Cult 2000 incubator (Hucoa-Erloss, Madrid, Spain). The cells were seeded at 24-multiwell dishes (Falcon, St. Louis, MO, USA). Experiments were performed with cells at $60 \%-70 \%$ of confluence. A suspension of $\mathrm{ZnO}$ particles (nanoZnO and NS-ZnO) was prepared in phosphate buffered saline (PBS). After that, ZnO concentration (0.2 $\mathrm{mg} / \mathrm{mL}$ ) was prepared in DMEM from the suspension in PBS. Cells were incubated for 24h with the appropriate concentration of $\mathrm{ZnO}$. After incubation, cells were washed three times with PBS and incubated again with DMEM for 24h. Finally, cell viability was determined after treatments by the (3-(4,5-dimethylthiazol-2-yl)-2,5-diphenyltetrazolium bromide, called as MTT assay. The MTT assay is a colorimetric method for measuring the activity of mitochondrial enzymes. The enzymes reduce the yellow MTT dye to its insoluble formazan, which has a purple color. Therefore, the amount of formazan formed is proportional to the number of living cells. To determine the cell survival, the $540 \mathrm{~nm}$ absorption band is measured in each assay. The results were expressed as a percentage in comparison with control cells.

\section{Associated Content}

\section{Supporting Information}

The Supporting Information is available free of charge on the ACS Publications website at DOI:

Generation of highly reactive species during photocatalysis process; Structural characterization of NS-ZnO; Porosity study of NS$\mathrm{ZnO}$; Evolution of the hierarchical structure with ultrasound treatment; Morphological characterization of starting ZnO; Morphological characterization of nanometric $\mathrm{ZnO}$; Antifungal activity of $\mathrm{NS}-\mathrm{ZnO}$ against Aspergillus niger; ROS detection in micrometric $\mathrm{ZnO}$ (dark gray) and nanometric $\mathrm{ZnO}$ (light gray) compared to $\mathrm{NS}-\mathrm{ZnO}$; Ultraviolet-visible study to determine the ZnO band gap; Study of surface composition of NS-ZnO, micrometric and nanometric ZnO references; Mechanism of NS-ZnO against Staphylococcus aureus.

\section{Acknowledgments}

This work was supported by the Spanish Ministry of Economy and Competitiveness (MINECO) under the projects MAT2017-86450-C4-1-R, and the Spanish National Research Council (CSIC) under the project NANOMIND CSIC 201560E068. Dr. P. Leret is also indebted to MINECO for a “Torres Quevedo" contract (ref: PTQ-12-05470), which is co- 
E. de Lucas-Gil, P. Leret, M. Monte-Serrano, J.J. Reinosa, E. Enríquez, A. Del Campo, M. Cañete, J. Menéndez, J.F. Fernández, F. Rubio-Marcos, ZnO Nanoporous Spheres with Broad-Spectrum Antimicrobial Activity by Physicochemical Interactions, ACS Appl. Nano Mater. 1 (2018) $3214-3225$. doi:10.1021/acsanm.8b00402.

financed with European Social Fund. Dr. E. Enriquez is also indebted to MINECO for a "Torres Quevedo" contract (ref: PTQ-14-07289), which is co-financed with European Social Fund. Dr. F. R-M is also indebted to MINECO for a 'Ramon y Cajal' contract (ref: RyC-2015-18626), which is co-financed by the European Social. The authors acknowledge the ESRF The European Synchrotron and the SpLine CRG BM25 beamline staff for provision of synchrotron radiation and for assistance during X-ray diffraction measurements (ref: 25-01-966). Finally, authors are grateful to Aida Serrano and Rocío Estefanía Rojas-Hernandez for scientific and technical advice in XANES measurements, $\mathrm{M}^{\mathrm{a}}$ José Velasco and Pilar Ortega for ICPOES measurements, Alexandra Muñoz-Bonilla for scientific advice and Laura Pascual for scientific and technical advice.

\section{Additional information}

Competing financial interests: The authors declare no competing financial interests.

\section{References}

(1) Lewicka, Z. A.; Benedetto, A. F.; Benoit, D. N.; Yu, W. W.; Fortner, J. D.; Colvin, V. L. The Structure, Composition, and Dimensions of $\mathrm{TiO} 2$ and $\mathrm{ZnO}$ Nanomaterials in Commercial Sunscreens. J. Nanoparticle Res. 2011, 13 (9), 3607-3617.

(2) Li, M.; Hu, Y.; Xie, S.; Huang, Y.; Tong, Y.; Lu, X. Heterostructured ZnO/SnO(2-x) Nanoparticles for Efficient Photocatalytic Hydrogen Production. Chem. Commun. 2014, 50 (33), 4341-4343.

(3) Lu, X.; Wang, G.; Xie, S.; Shi, J.; Li, W.; Tong, Y.; Li, Y. Efficient Photocatalytic Hydrogen Evolution over Hydrogenated ZnO Nanorod Arrays. Chem. Commun. 2012, 48 (62), 7717-7719.

(4) Becheri, A.; Dürr, M.; Lo Nostro, P.; Baglioni, P. Synthesis and Characterization of Zinc Oxide Nanoparticles: Application to Textiles as UV-Absorbers. J. Nanoparticle Res. 2008, 10 (4), 679-689.

(5) Espitia, P. J. P.; Soares, N. de F. F.; Coimbra, J. S. dos R.; de Andrade, N. J.; Cruz, R. S.; Medeiros, E. A. A. Zinc Oxide Nanoparticles: Synthesis, Antimicrobial Activity and Food Packaging Applications. Food Bioprocess Technol. 2012, 5 (5), 14471464.

(6) Weintraub, B.; Zhou, Z.; Li, Y.; Deng, Y. Solution Synthesis of One-Dimensional ZnO Nanomaterials and Their Applications. Nanoscale 2010, 2 (9), 1573.

(7) Hajipour, M. J.; Fromm, K. M.; Akbar Ashkarran, A.; Jimenez de Aberasturi, D.; Larramendi, I. R. de; Rojo, T.; Serpooshan, V.; Parak, W. J.; Mahmoudi, M. Antibacterial Properties of Nanoparticles. Trends Biotechnol. 2012, 30 (10), 499-511.

(8) Andersson, D. I.; Hughes, D. Antibiotic Resistance and Its Cost: Is It Possible to Reverse Resistance? Nat. Rev. Microbiol. 2010, 8 (4), 260-271.

(9) Zheng, K.; Setyawati, M. I.; Leong, D. T.; Xie, J. Antimicrobial Silver Nanomaterials. Coord. Chem. Rev. 2018, 357, 1-17.

(10) Chen, X.; Schluesener, H. J. Nanosilver: A Nanoproduct in Medical Application. Toxicol. Lett. 2008, 176, 1-12.

(11) Sotiriou, G. A.; Pratsinis, S. E. Antibacterial Activity of Nanosilver Ions and Particles. Environ. Sci. Technol. 2010, 44 (14), 56495654.

(12) Park, H.-J.; Kim, J. Y.; Kim, J.; Lee, J.-H.; Hahn, J.-S.; Gu, B.; Yoon, J.; Superoxide, B.; Coli, E.; Aureus, S. Silver-Ion-Mediated Reactive Oxygen Species Generation Affecting Bactericidal Activity. Water Res. 2008, 43, 1027-1032.

(13) Ercal, N.; Gurer-Orhan, H.; Aykin-Burns, N. Toxic Metals and Oxidative Stress Part I: Mechanisms Involved in Metal Induced Oxidative Damage. Curr. Top. Med. Chem. 2001, 1 (6), 529-539.

(14) Morones, J. R.; Elechiguerra, J. L.; Camacho, A.; Holt, K.; Kouri, J. B.; Ramírez, J. T.; Yacaman, M. J. The Bactericidal Effect of Silver Nanoparticles. Nanotechnology 2005, 16 (10), 2346-2353.

(15) Panáček, A.; Kvítek, L.; Smékalová, M.; Večeřová, R.; Kolář, M.; Röderová, M.; Dyčka, F.; Šebela, M.; Prucek, R.; Tomanec, O.; Zbořil, R. Bacterial Resistance to Silver Nanoparticles and How to Overcome It. Nat. Nanotechnol. 2018, 13 (1), 65-71.

(16) Sawai, J. Quantitative Evaluation of Antibacterial Activities of Metallic Oxide Powders ( $\mathrm{ZnO}, \mathrm{MgO}$ and $\mathrm{CaO})$ by Conductimetric Assay. J. Microbiol. Methods 2003, 54 (2), 177-182.

(17) Azam, A.; Ahmed, A. S.; Oves, M.; Khan, M. S.; Habib, S. S.; Memic, A. Antimicrobial Activity of Metal Oxide Nanoparticles against Gram-Positive and Gram-Negative Bacteria: A Comparative Study. Int. J. Nanomedicine 2012, 7 (March 2016), 6003-6009.

(18) Jan, T.; Iqbal, J.; Ismail, M.; Badshah, N.; Mansoor, Q.; Arshad, A.; Ahkam, Q. M. Synthesis, Physical Properties and Antibacterial Activity of Metal Oxides Nanostructures. Mater. Sci. Semicond. Process. 2014, 21 (1), 154-160.

(19) Brayner, R.; Ferrari-Iliou, R.; Brivois, N.; Djediat, S.; Benedetti, M. F.; Fiévet, F. Toxicological Impact Studies Based on Escherichia Coli Bacteria in Ultrafine ZnO Nanoparticles Colloidal Medium. Nano Lett. 2006, 6 (4), 866-870.

(20) Jones, N.; Ray, B.; Ranjit, K. T.; Manna, A. C. Antibacterial Activity of ZnO Nanoparticle Suspensions on a Broad Spectrum of Microorganisms. FEMS Microbiol. Lett. 2008, 279 (1), 71-76.

(21) Li, M.; Zhu, L.; Lin, D. Toxicity of ZnO Nanoparticles to Escherichia Coli: Mechanism and the Influence of Medium Components. Environ. Sci. Technol. 2011, 45 (5), 1977-1983.

(22) He, L.; Liu, Y.; Mustapha, A.; Lin, M. Antifungal Activity of Zinc Oxide Nanoparticles against Botrytis Cinerea and Penicillium Expansum. Microbiol. Res. 2011, 166 (3), 207-215.

(23) de Lucas-Gil, E.; Fernández, J. F.; Rubio-Marcos, F. One More Step against Nanotoxicity: Hierarchical Particles Designed to Antifungal Properties. Mater. Des. 2017, 134, 188-195.

(24) Padmavathy, N.; Vijayaraghavan, R. Enhanced Bioactivity of ZnO Nanoparticles - an Antimicrobial Study. Sci. Technol. Adv. Mater. 2008, 9 (3), 035004.

(25) Raghupathi, K. R.; Koodali, R. T.; Manna, A. C. Size-Dependent Bacterial Growth Inhibition and Mechanism of Antibacterial 
E. de Lucas-Gil, P. Leret, M. Monte-Serrano, J.J. Reinosa, E. Enríquez, A. Del Campo, M. Cañete, J. Menéndez, J.F. Fernández, F. Rubio-Marcos, ZnO Nanoporous Spheres with Broad-Spectrum Antimicrobial Activity by Physicochemical Interactions, ACS Appl. Nano Mater. 1 (2018) $3214-3225$. doi:10.1021/acsanm.8b00402.

Activity of Zinc Oxide Nanoparticles. Langmuir 2011, 27 (7), 4020-4028.

(26) Yamamoto, O. Influence of Particle Size on the Antibacterial Activity of Zinc Oxide. Int. J. Inorg. Mater. 2001, 3 (7), 643-646.

(27) Pan, C.; Dong, L.; Qu, B.; Wang, J. Facile Synthesis and Enhanced Photocatalytic Performance of 3D ZnO Hierarchical Structures. J. Nanosci. Nanotechnol. 2011, 11 (6), 5042-5048.

(28) Yin, L.-W.; Bando, Y.; Zhan, J.-H.; Li, M.-S.; Golberg, D. Self-Assembled Highly Faceted Wurtzite-Type ZnS Single-Crystalline Nanotubes with Hexagonal Cross-Sections. Adv. Mater. 2005, 17 (16), 1972-1977.

(29) Zhang, L.; Jiang, Y.; Ding, Y.; Daskalakis, N.; Jeuken, L.; Povey, M.; O’Neill, A. J.; York, D. W. Mechanistic Investigation into Antibacterial Behaviour of Suspensions of ZnO Nanoparticles against E. Coli. J. Nanoparticle Res. 2010, 12 (5), $1625-1636$.

(30) Shi, L.-E.; Li, Z.-H.; Zheng, W.; Zhao, Y.-F.; Jin, Y.-F.; Tang, Z.-X. Synthesis, Antibacterial Activity, Antibacterial Mechanism and Food Applications of ZnO Nanoparticles: A Review. Food Addit. Contam. Part A. Chem. Anal. Control. Expo. Risk Assess. 2014, 31 (2), 173-186.

(31) Kumar, R.; Umar, A.; Kumar, G.; Nalwa, H. S. Antimicrobial Properties of ZnO Nanomaterials: A Review. Ceram. Int. 2017, 43 (5), 3940-3961.

(32) Li, Y.; Zhang, W.; Niu, J.; Chen, Y. Mechanism of Photogenerated Reactive Oxygen Species and Correlation with the Antibacterial Properties of Engineered Metal-Oxide Nanoparticles. ACS Nano 2012, 6 (6), 5164-5173.

(33) Sirelkhatim, A.; Mahmud, S.; Seeni, A.; Kaus, N. H. M.; Ann, L. C.; Bakhori, S. K. M.; Hasan, H.; Mohamad, D. Review on Zinc Oxide Nanoparticles: Antibacterial Activity and Toxicity Mechanism. Nano-Micro Lett. 2015, 7 (3), $219-242$

(34) Pasquet, J.; Chevalier, Y.; Pelletier, J.; Couval, E.; Bouvier, D.; Bolzinger, M.-A. The Contribution of Zinc Ions to the Antimicrobial Activity of Zinc Oxide. Colloids Surfaces A Physicochem. Eng. Asp. 2014, 457, $263-274$.

(35) Jiang, Y.; Zhang, L.; Wen, D.; Ding, Y. Role of Physical and Chemical Interactions in the Antibacterial Behavior of ZnO Nanoparticles against E. Coli. Mater. Sci. Eng. C 2016, 69, 1361-1366.

(36) Nel, A. E.; Mädler, L.; Velegol, D.; Xia, T.; Hoek, E. M. V; Somasundaran, P.; Klaessig, F.; Castranova, V.; Thompson, M. Understanding Biophysicochemical Interactions at the Nano-Bio Interface. Nat. Mater. 2009, 8 (7), $543-557$.

(37) Nel, A.; Xia, T.; Mädler, L.; Li, N. Toxic Potential of Materials at the Nanolevel. Science (80-. ). 2006, 311 (5761), 622-627.

(38) Sharifi, S.; Behzadi, S.; Laurent, S.; Laird Forrest, M.; Stroeve, P.; Mahmoudi, M. Toxicity of Nanomaterials. Chem. Soc. Rev. 2012, $41(6), 2323-2343$.

(39) Boyjoo, Y.; Wang, M.; Pareek, V. K.; Liu, J.; Jaroniec, M. Synthesis and Applications of Porous Non-Silica Metal Oxide Submicrospheres. Chem. Soc. Rev. Chem. Soc. Rev 2016, 45 (45), 6013-6047.

(40) Vergés, M. A.; Mifsud, A.; Serna, C. J. Formation of Rod-like Zinc Oxide Microcrystals in Homogeneous Solutions. J. Chem. Soc., Faraday Trans. 1990, 86 (6), 959-963.

(41) Nakamoto, K. Infrared and Raman Spectra of Inorganic and Coordination Compounds, Sixth.; John Wiley \& Sons, Inc.: Hoboken, NJ, USA, 2008.

(42) Bortolani, F.; Del Campo, A.; Fernandez, J. F.; Clemens, F.; Rubio-Marcos, F. High Strain in (K,Na)NbO3-Based Lead-Free Piezoelectric Fibers. Chem. Mater. 2014, 26 (12), 3838-3848.

(43) De Jonghe, L. C.; Rahaman, M. N. Sintering of Ceramics. In Handbook of Advanced Ceramics: Materials, Applications, Processing and Properties; 2003; pp 187-264.

(44) de Lucas-Gil, E.; Reinosa, J. J.; Neuhaus, K.; Vera-Londono, L.; Martín-González, M.; Fernández, J. F.; Rubio-Marcos, F. Exploring New Mechanisms for Effective Antimicrobial Materials: Electric Contact-Killing Based on Multiple Schottky Barriers. ACS Appl. Mater. Interfaces 2017, 9 (31), 26219-26225.

(45) Huang, N.; Shu, J.; Wang, Z.; Chen, M.; Ren, C.; Zhang, W. One-Step Pyrolytic Synthesis of ZnO Nanorods with Enhanced Photocatalytic Activity and High Photostability under Visible Light and UV Light Irradiation. J. Alloys Compd. 2015, 648, 919929

(46) Kaur, J.; Bansal, S.; Singhal, S. Photocatalytic Degradation of Methyl Orange Using ZnO Nanopowders Synthesized via Thermal Decomposition of Oxalate Precursor Method. Phys. B Condens. Matter 2013, 416, 33-38.

(47) Richard, C.; Boule, P. Reactive Species Involved in Photocatalytic Transformations on Zinc Oxide. Sol. Energy Mater. Sol. Cells 1995, 38 (1-4), 431-440.

(48) Shinde, S. S.; Shinde, P. S.; Bhosale, C. H.; Rajpure, K. Y. Zinc Oxide Mediated Heterogeneous Photocatalytic Degradation of Organic Species under Solar Radiation. J. Photochem. Photobiol. B Biol. 2011, 104 (3), 425-433.

(49) Arakha, M.; Saleem, M.; Mallick, B. C.; Jha, S. The Effects of Interfacial Potential on Antimicrobial Propensity of ZnO Nanoparticle. Sci. Rep. 2015, 5, 9578.

(50) Lorite, I.; Martín-González, M. S.; Romero, J. J.; García, M. A.; Fierro, J. L. G.; Fernández, J. F. Electrostatic Charge Dependence on Surface Hydroxylation for Different Al 2O 3 Powders. Ceram. Int. 2012, 38 (2), 1427-1434.

(51) Lorite, I.; Romero, J. J.; Fernandez, J. F. Influence of the Nanoparticles Agglomeration State in the Quantum-Confinement Effects: Experimental Evidences. AIP Adv. 2015, 5 (3), 037105.

(52) Giri, P. K.; Bhattacharyya, S.; Singh, D. K.; Kesavamoorthy, R.; Panigrahi, B. K.; Nair, K. G. M. Correlation between Microstructure and Optical Properties of ZnO Nanoparticles Synthesized by Ball Milling. J. Appl. Phys. 2007, 102 (9), 093515.

(53) Cuscó, R.; Alarcón-Lladó, E.; Ibáñez, J.; Artús, L.; Jiménez, J.; Wang, B.; Callahan, M. J. Temperature Dependence of Raman Scattering in ZnO. Phys. Rev. B 2007, 75 (16), 165202.

(54) Rubio-Marcos, F.; Quesada, A.; García, M. a.; Bañares, M. a.; Fierro, J. L. G.; Martín-Gonzalez, M. S.; Costa-Krämer, J. L.; Fernández, J. F. Some Clues about the Interphase Reaction between $\mathrm{ZnO}$ and $\mathrm{MnO}_{2}$ Oxides. J. Solid State Chem. 2009, 182 (5), 1211-1216.

(55) Al-Gaashani, R.; Radiman, S.; Daud, A. R.; Tabet, N.; Al-Douri, Y. XPS and Optical Studies of Different Morphologies of ZnO Nanostructures Prepared by Microwave Methods. Ceram. Int. 2013, 39 (3), 2283-2292.

(56) Fan, J. C. C.; Goodenough, J. B. X-Ray Photoemission Spectroscopy Studies of Sn-Doped Indium-Oxide Films. J. Appl. Phys. 1977, $48(8), 3524$

(57) Das, J.; Pradhan, S. K.; Sahu, D. R.; Mishra, D. K.; Sarangi, S. N.; Nayak, B. B.; Verma, S.; Roul, B. K. Micro-Raman and XPS Studies of Pure ZnO Ceramics. Phys. B Condens. Matter 2010, 405 (10), 2492-2497.

(58) Lee, J.; Chung, J.; Lim, S. Improvement of Optical Properties of Post-Annealed ZnO Nanorods. Phys. E Low-Dimensional Syst. Nanostructures 2010, 42 (8), 2143-2146.

Yang, X.-J.; Miao, X.-Y.; Xu, X.-L.; Xu, C.-M.; Xu, J.; Liu, H.-T. Structure, X-Ray Photoelectron Spectroscopy and 
E. de Lucas-Gil, P. Leret, M. Monte-Serrano, J.J. Reinosa, E. Enríquez, A. Del Campo, M. Cañete, J. Menéndez, J.F. Fernández, F. Rubio-Marcos, ZnO Nanoporous Spheres with Broad-Spectrum Antimicrobial Activity by Physicochemical Interactions, ACS Appl. Nano Mater. 1 (2018) $3214-3225$. doi:10.1021/acsanm.8b00402.

Photoluminescence Properties of Highly Ordered ZnO Microrods. Opt. Mater. (Amst). 2005, 27 (10), 1602-1605.

(60) Lorite, I.; Díaz-Carrasco, P.; Gabás, M.; Fernández, J. F.; Costa-Krämer, J. L. Correlation between Intrinsic Defect and Carrier Transport in ZnO Thin Films by Confocal Raman Spectroscopy. Mater. Lett. 2013, 109, 167-171.

(61) Zhang, L.; Ding, Y.; Povey, M.; York, D. ZnO Nanofluids-A Potential Antibacterial Agent. Prog. Nat. Sci. 2008, 18 (8), $939-944$.

(62) Zhang, L.; Jiang, Y.; Ding, Y.; Povey, M.; York, D. Investigation into the Antibacterial Behaviour of Suspensions of ZnO Nanoparticles (ZnO Nanofluids). J. Nanoparticle Res. 2007, 9 (3), 479-489. 